\title{
Modelagem Sistêmica e Planejamento Logístico da Cadeia de Suprimentos de Petróleo
}

\author{
Ricardo Terumichi Ono, Rui Carlos Botter \\ ricono@usp.br, rcbotter@usp.br \\ Departamento de Engenharia Naval e Oceânica da \\ Escola Politécnica da Universidade de São Paulo
}

São Paulo 2007

\begin{abstract}
Resumo
O estudo da cadeia de suprimentos do petróleo envolve uma série de subsistemas que interagem entre si nos processos de exploração, transferência do petróleo para os terminais, armazenagem em tanques e transferência para as refinarias. Nesse contexto, o presente trabalho pretende examinar as características dos principais subsistemas que compõem o segmento upstream, cujo escopo abrange desde o subsistema de produção das plataformas até o envio do petróleo para as refinarias, com destaque para o subsistema de transporte marítimo que é o elo vital e talvez o maior gargalo no escoamento do petróleo. A metodologia a ser empregada compatibiliza decisões em níveis de planejamento hierárquico distintos, buscando inicialmente identificar o dimensionamento dos principais recursos no plano estratégico e posteriormente efetuar a programação dos mesmos em nível tático/operacional. Os modelos computacionais foram desenvolvidos utilizando o software ARENA, versão 5.0. e o CPLEX, versão 10.0, para os modelos de simulação e otimizante, respectivamente. O modelo otimizante foi adotado para ratificar ou aprimorar o resultado apresentado pelo modelo de simulação, completando a ferramenta de apoio à decisão que possibilita analisar cada cenário rodado e compor o projeto da cadeia de suprimentos de petróleo.
\end{abstract}

Palavras-Chave: Cadeia de Suprimento, Petróleo, Simulação, Otimização.

\begin{abstract}
The study of the petroleum supply chain involves several subsystems that interact among themselves in the whole processes, since the oil production, transportation for the terminals, storage in tanks and transfers for the refineries. In this context, this thesis aims to study the main characteristics of these subsystems that compound the upstream segment, comprised from petroleum production by platforms up till the dispatch to refineries, with distinction to the transportation subsystem. The adopted methodology join decisions based in different hierarchy planning, starting with the evaluating the main resources at the strategic plan and afterwards, take a programming decision on tatic/operational plans. Models developments used two approaches: simulation and optimization. These models were developed in ARENA, v.5 and CPLEX, v. 10.0, for the simulation and optimization models, respectively. The optimization model was adopted for corroborate the simulation results concluding the decision support tool and compound the petroleum supply chain project.
\end{abstract}

Keywords: Supply Chain, Petroleum, Simulation, Optimization 


\section{INTRODUÇÃO}

O estudo da cadeia de suprimentos do petróleo envolve uma série de subsistemas que interagem entre si nos processos de exploração, de transferência do petróleo para os terminais, de armazenagem em tanques e de transferência para as refinarias para finalmente iniciar o processo de refino e produção dos derivados de petróleo. Tais subsistemas devem ser estudados com grau de detalhe que permita elucidar as principais características que regem cada um dos processos, buscando identificar condições ideais, ótimas e, principalmente, as interferências que ocorrem dentro e entre cada um deles.

A exploração e produção do petróleo tem sido um dos focos de maior relevância na área de energia, visto que o país almeja cada vez mais aumentar sua capacidade produtiva visando a uma condição de auto-sustentabilidade. Nesse contexto, a política de desenvolvimento que vem sendo adotada no setor, iniciada há duas décadas, tem buscado aos poucos a desestatização do setor através da abertura do mercado, estimulando a entrada de novos conglomerados de forma a quebrar o monopólio do setor, cuja conseqüência direta é o aumento dos investimentos estrangeiros.

Nesse contexto, o presente trabalho pretende examinar minuciosamente as características dos principais subsistemas que compõem a cadeia de suprimentos do petróleo, cujo escopo abrange desde a produção das plataformas na Bacia de Campos até o envio do petróleo para as refinarias através de dutos.

A cadeia de agregação de valores do petróleo necessita de ser constantemente monitorada e revista, pois ela é a chave do sucesso de todo o processo. Para se ter esse controle é necessário que haja ferramentas de apoio às decisões (SADs) aptas a mostrarem informações para que a decisão seja tomada corretamente. As variáveis de decisão que influem nesse processo macro poderiam ser resumidas em: quais produtos e em que quantidades serão produzidas ou compradas; serão vendidos ou armazenados, serão transferidos ou consumidos; finalmente, quando e como tudo isso deve ocorrer.

A combinação destas variáveis de decisão é que dará subsídios suficientes para um bom acompanhamento e gestão da cadeia do petróleo. Assim, uma ferramenta capaz de adquirir as informações, integrar os dados adequadamente e avaliar as capacidades dos recursos deverá ser um grande trunfo para este campo de estudo.

\section{Descrição do Problema}

O problema a ser estudado consiste na cadeia de suprimentos do petróleo, no segmento upstream, delimitado pelo subsistema de produção e exploração do petróleo a partir das plataformas, o escoamento do petróleo através de uma frota de navios, atendimento dos mesmos pelos terminais situados na costa e bombeamento do petróleo para as refinarias. O sistema de armazenagem nas refinarias não faz parte do escopo estudado. A figura 1 ilustra o escopo do problema abordado.

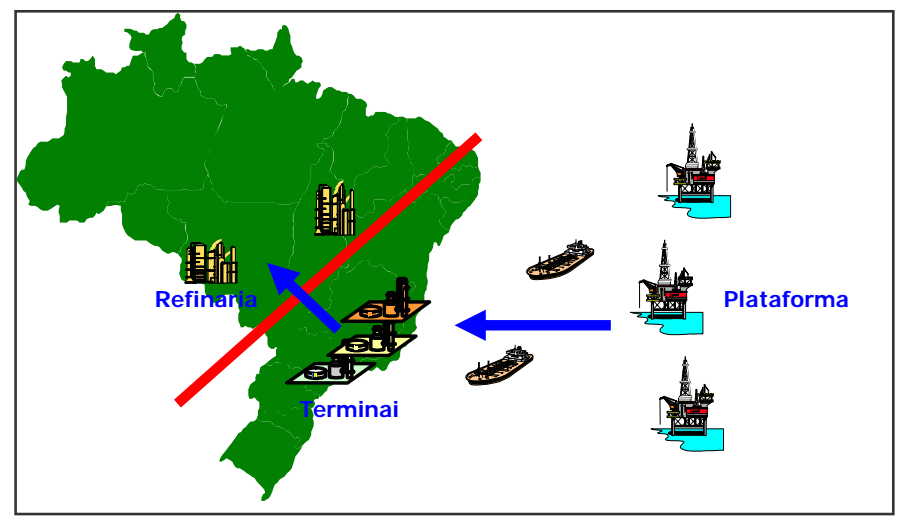

Figura 1. Escopo do Problema

O enfoque a ser dado ao problema pode ser dividido sob três aspectos: ambiente e infraestrutura, veículos e operação e controle:

1. Ambiente e Infra-estrutura: Consiste na especificação dos principais recursos envolvidos neste escopo e os condicionantes operacionais a que as atividades são submetidas.

a. Unidades Marítimas (plataformas): Localizadas em alto mar, realizam a exploração, produção e armazenagem do petróleo. As unidades marítimas podem ou não estar providas de tanques de armazenagem. Unidades que mantém baixa produção são conectadas através de dutos marítimos à 
plataforma mais próxima para armazenagem de sua produção, ou o alívio é feito apenas no atendimento à embarcação. A plataforma produz um único tipo de petróleo, determinada pelas características do solo e profundidade em que ela se encontra. A decisão de produção passa inicialmente por detalhadas avaliações de riscos e viabilidade econômico-operacional, quando são estudadas as condições sísmicas, características físico-químicas dos bolsões de petróleo, potencialidades de produção e escoamento. Tal decisão ainda contempla o volume a ser produzido durante o horizonte de planejamento, podendo acelerar ou retardar a produção, através do aumento ou diminuição de poços a serem perfurados. As atividades inerentes à decisão de perfuração e exploração não são contempladas nesse estudo. Decisões posteriores, como definição dos volumes a serem produzidas por cada plataforma, seleções das plataformas candidatas, sob o critério de escoamento logístico são objetos desse estudo; isto é, a partir de uma configuração previamente estudada ou existente, será possível estudar a cadeia de suprimentos que contemplará o cenário a ser avaliado. O principal critério e mais usual no processo de produção é o de evitar perdas operacionais nas plataformas, ou seja, garantir que as plataformas produzam o petróleo de forma contínua, sem interrupção. Tal premissa é adotada no desenvolvimento desse estudo.

b. Terminais: Localizados na costa, representam os pontos de descarga do petróleo extraído nas unidades marítimas. Cada terminal possui a infra-estrutura de atendimento necessário para atendimento dos navios e bombeamento para as refinarias. Existem restrições quanto ao número e extensão de berços de atracação, que limita a classe de embarcação. Os tanques de armazenagem estão interligados através de dutos para descarga dos navios, cuja taxa de descarga é determinada e constante. Os tanques são dedicados por tipo de petróleo, isto é, não deve haver misturas, para não comprometer as características físico-quimicas do petróleo. O alivio dos tanques é feito através do bombeamento direto para as refinarias, realizadas como "seqüências de bateladas", definidas pelo tipo do petróleo, o intervalo de tempo do bombeamento e a vazão correspondente. De forma análoga ao critério estabelecido para as plataformas, a indisponibilidade do petróleo na condição da batelada implica em perda operacional e necessidade de interrupção do bombeamento, devendo ser evitada em qualquer nível de planejamento.

c. Refinarias: Localizadas próximas aos terminais e estão interligadas à estas por meio de dutos terrestres. Representam as plantas industriais para processamento do petróleo recebido pelos terminais. O escopo do presente trabalho é limitado ao bombeamento do petróleo até a refinaria. Não são tratados os sistemas de armazenagem do petróleo nas refinarias. Consideram-se como demanda das refinarias, as disciplinas de bombeamento pelos terminais.

d. Condições Meteorológicas: Fator ambiental que restringe a continuidade das operações de atendimento dos navios nas plataformas e terminais. Sobretudo nas plataformas, as condições meteorológicas impedem ou retardam o procedimento de atracação e conexão dos mangotes de alívio do navio. Dessa forma, as plataformas e terminais estão sujeitas em graus diferentes de restrições de atendimento e que serão consideradas no estudo.

2. Veículos: Trata-se do principal elo da cadeia de suprimentos, atribuído aos navios que realizam o escoamento do petróleo entre plataformas e terminais. Os navios que executam essa tarefa são classificados segundo suas características físicas, dentre as quais destacam-se: dimensões, capacidade dos porões, velocidades e custos diários. O detalhamento das características e suas funções são tratados em BORGES (2000). O foco central do presente trabalho trata o dimensionamento e posterior programação da frota de navios necessários para o atendimento das condições de demanda determinados pelas plataformas e pelos terminais. Busca-se atribuir as viagens dos navios da forma mais adequada, visando o melhor aproveitamento da frota no escoamento do petróleo. As viagens dos navios não se restringem às viagens entre plataformas e terminais, mas é possível que se realizem viagens entre plataformas e entre terminais. Isto é, podem existir condições em que os navios sejam designados a efetuar carregamentos múltiplos entre terminais, podendo carregar até tipos distintos de petróleos. Analogamente, podem-se efetuar viagens entre terminais para atendimentos fracionados ou de tipos de petróleos distintos. Diante de uma configuração pré-determinada de frota de navios, existem inúmeras possibilidades de alocação de carga e viagens para o cumprimento das demandas estabelecidas. Dessa forma, o estudo pretende explorar o conjunto de soluções viáveis para um planejamento adequado no dimensionamento e programação dos navios.

3. Operação e Controle: As operações que envolvem o escoamento do petróleo e que serão exploradas no presente trabalho consistem nas atividades de produção e armazenagem do petróleo e programação de navios. O escoamento do petróleo é realizado primordialmente visando minimizar a incidência de perdas, que podem ocorrer nos terminais e nas plataformas: a primeira, quando ocorre indisponibilidade do petróleo para o bombeamento e a segunda pelo excedente de petróleo produzido e indisponibilidade de armazenagem do mesmo. Para que tais situações sejam evitadas, é necessário manter uma configuração adequada no dimensionamento dos recursos envolvidos: plataformas, terminais e frota de navios de forma que os níveis dos tanques se mantenham nos limites superiores e inferiores 
aceitáveis e seguros. Define-se níveis de segurança nos tanques pela denominação de “TOP”, que delimita a condição máxima adversa de operação em segurança. Consiste nos níveis próximos aos da capacidade dos tanques na plataforma e aos níveis próximos aos mínimos dos tanques dos terminais. Com relação à operação e controle dos navios, o foco do problema recai sobre a programação dos mesmos, que visa buscar os roteiros de viagens ao menor custo, mantendo-se os níveis dos tanques nas condições seguras.

Dessa forma, a cadeia de suprimentos do petróleo , que é foco do presente estudo abrange as operações envolvidas no escoamento do petróleo, a partir das plataformas, até o bombeamento para as refinarias, excluindo-se o sistema de armazenagem nas refinarias.

\section{Objetivos}

No contexto apresentado, o presente trabalho encaixa-se no sentido de desenvolver metodológica e sistematicamente ferramentas hábeis para o planejamento logístico integrado das atividades upstream que envolvem a cadeia de suprimentos tendo como meta o estabelecimento do projeto da cadeia de suprimentos, composto pelo planejamento e programação.

A partir dessa visão geral dos processos envolvidos no suprimento de petróleo às refinarias, é possível destacar os seguintes objetivos:

\section{Com relação à avaliação em nível estratégico:}

$\checkmark$ Análise de Capacidade de Recursos - A partir da projeção de crescimento da produção nos próximos anos, ou seja, dos projetos de desenvolvimento previstos e em andamento, avaliar a necessidade de aumento de frota, dutos submarinos e terrestres, terminal marítimo norte fluminense e outros;

$\checkmark$ Análise do Impacto de Políticas / Procedimentos Operacionais - políticas poderão ser avaliadas, como, por exemplo, testar a política de tolerância zero com respeito ao meio ambiente no tamanho requerido da frota, testar a manutenção de um estoque mínimo de petróleo maior nas refinarias avaliando o nível de serviço obtido pelo sistema logístico, verificar a mudança da mistura de petróleo alocada às refinarias com vistas aos desdobramentos no desempenho do sistema logístico, entre outros;

$\checkmark$ Propor e Testar Parâmetros Limitantes ou "Benchmark" - para as diversas operações-padrão das etapas do suprimento, determinar os parâmetros de produtividade sob determinadas condições, como por exemplo, a amarração/desamarração de navios junto às monobóias, FSO e FPSO, em função de condições climáticas e de mar.

\section{Com relação à avaliação em nível tático/operacional:}

$\checkmark$ Programação Ótima da Frota - possibilitar o planejamento logístico de curto prazo, através da identificação da configuração ideal no atendimento das demandas propostas, estabelecendo as características das viagens a serem executadas pela frota visando a operacionalização da solução. objetivos

A figura esquemática 2 ilustra as atribuições dos dois níveis de planejamento e os respectivos

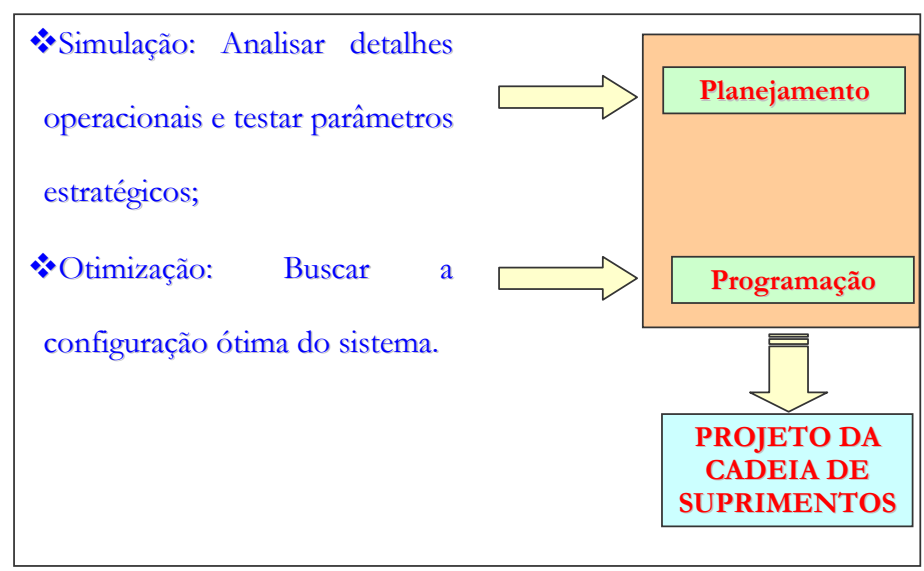

Figura 2. Objetivos. 
O conjunto de modelos desenvolvidos resultará em uma ferramenta de planejamento e análise, cujos usuários poderão ser os setores de planejamento estratégico, tático e até operacional da empresa que detém os controles dos principais ativos envolvidos e dos campos maduros. Pretende-se que o trabalho traga uma valiosa contribuição também para a agência reguladora (ANP) no sentido de oferecer uma ferramenta de controle e análise da produtividade em quaisquer processos inseridos na cadeia e principalmente para planejamento futuro e estabelecimento de novas metas de produção e escoamento do petróleo. A tabela 1 mostra sucintamente as características e atribuições de cada modelo.

Tabela 1 . Atribuição das Técnicas

\begin{tabular}{||c|c|c||}
\hline \hline Modelagem & Simulação & Otimização \\
\hline \hline Nível Hierárquico de decisão & Estratégico & Tático/Operacional \\
\hline \hline Horizonte de Planejamento & 1 ano & até 30 dias \\
\hline Objetivo & Dimensionamento de Recursos & Programação dos Recursos \\
\hline Função & Avaliação/Testes de Cenários & Busca solução Ótima \\
\hline \hline
\end{tabular}

\section{MÉTODOS DE RESOLUÇÃO}

A resolução de um problema adotando-se a metodologia de enfoque sistêmico requer uma abordagem diferenciada e específica para cada um dos subsistemas considerados. Tais considerações individuais dos subsistemas, naturalmente, permitem explorar os processos que os regem em um grau maior de detalhe permitindo inicialmente levantar todas as possíveis restrições que afetam o problema, sem se preocupar com a relevância no sistema global.

A análise individual de cada subsistema poderá e usualmente deverá incorrer em erros ou inconsistências, pois em muitos casos a delimitação das fronteiras da região de controle do sistema não é claramente definida.

Nesse contexto, a metodologia de simulação permite uma abordagem discreta dos eventos através da modelagem individual dos subsistemas e integração posterior, de acordo com a viabilidade dos dados e das respostas requeridas para utilização nos módulos de otimização.

A modelagem matemática adotada para a resolução do presente problema pode ser dividida em duas grandes etapas, segundo o critério da técnica de modelagem: a de simulação probabilística e a de programação linear. Conforme descrito no capítulo referente à metodologia, a primeira etapa do trabalho consiste no desenvolvimento de um modelo computacional de simulação cujo principal objetivo é o entendimento das interferências entre os subsistemas e identificação dos gargalos através de análises de cenários a partir de um conjunto de dados pré-estabelecidos.

A partir do modelo de simulação, também será possível avaliar o grau de relevância de cada um dos parâmetros de entrada e os impactos na modificação dos mesmos. Por exemplo, saber qual seria o impacto na cadeia de um aumento da demanda de um determinado tipo de petróleo em uma determinada refinaria, analogamente, quais seriam os subsistemas mais afetados, os novos gargalos, as novas restrições. Além disso, será possível avaliar quantitativamente tais ocorrências.

Posteriormente, a partir das analises dos parâmetros, será possível definir claramente as variáveis de decisão que irão compor o modelo otimizante.

\section{O modelo de simulação}

A modelagem utilizando a técnica de simulação probabilística mostrou-se como sendo a mais adequada em função das características do problema e dos objetivos propostos. Segundo PIDD (1989), dentre as principais formas de modelagem, a simulação deve ser aplicada nos casos em que o sistema a ser estudado apresenta um enfoque dinâmico, sujeito à variação das condições no tempo e interativo. De acordo com o autor, quando não existe uma linearidade explícita dos processos do sistema de tal forma que atividades ocorrem simultaneamente e interferem entre si. Essa linearidade é complexa em termos de dimensão do problema, com uma vasta quantidade de informações, regras e procedimentos específicos que devem ser modelados. No modelo de simulação, o porte ou o tamanho do modelo e do número de variáveis é contabilizado diferentemente dos modelos heurísticos e de programação linear. Em outros termos, o dado associado a uma variável ou parâmetro pode ser vetorial e estar armazenado de formas alternativas como, por exemplo, através de atributos, variáveis e/ou expressões simples ou compostas. Segundo NERSESIAN; SWARTZ (1996), o modelo desenvolvido pode ser chamado de combinado, pelo 
fato de fazer uso de expressões para definir algumas variáveis do processo. Assim, no modelo de simulação, define-se o termo entidade, que corresponde ao objeto ou ente que receberá as instruções e atribuições dentro da lógica modelada no sistema. A entidade pode “carregar” informações que são utilizadas ao longo das decisões que compõem a lógica do modelo. A metodologia a ser adotada no desenvolvimento da presente etapa seguirá a já consagrada metodologia de PEDGEN (1995), que compreende as etapas de definição do problema, planejamento do projeto, definição do sistema, formulação do modelo conceitual, projeto preliminar, análise dos dados, tradução do modelo, verificação e validação, projeto final, experimentações, análise e interpretação dos resultados, implementação e documentação.

\section{O modelo conceitual}

O modelo de simulação desenvolvido é composto por cerca de quatorze rotinas ou lógicas de decisão, cada uma com sua respectiva função, que em conjunto apresenta o modelo global da cadeia de suprimentos do petróleo na bacia de Campos. As quatorze rotinas podem ser subdivididas em duas grandes categorias, a saber:

$\checkmark$ Rotinas inerentes à preparação de dados, atualização e atribuição das condições externas a que estarão sujeitas as entidades: leitura e gravação dos dados iniciais, condições meteorológicas, determinação das horas operacionais (dia/noite) e impressão de resultados.

$\checkmark$ Rotinas dos processos que compõem a cadeia de suprimentos: atendimento dos navios, processos de produção do petróleo nas plataformas, transporte, atendimento dos navios e bombeamento do petróleo para as refinarias.

Esta técnica apresenta as seguintes vantagens:

$\checkmark$ Análise sistêmica (considera todas as inter-relações dos diversos subsistemas e componentes do sistema logístico);

$\checkmark$ Avalia toda e qualquer modificação que eventualmente possa ser feita ao sistema;

$\checkmark$ Identifica gargalos nos processos e entre subsistemas;

$\checkmark$ Incorpora as características dinâmicas e as aleatoriedades dos processos.

A figura 1 ilustra o cenário de animação do modelo de simulação desenvolvido.

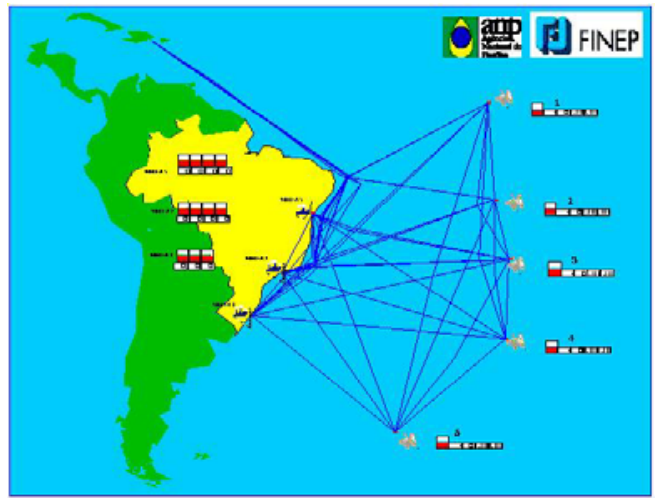

Figura1. Animação do Modelo

\section{RESULTADOS}

Os resultados imediatos e possíveis de serem verificadas ao final da execução do modelo dizem respeito ao dimensionamento da frota de navios e das capacidades e subdivisões dos tanques de armazenagem nas plataformas e nos terminais terrestres. Foi possível verificar que os gargalos aqui encontrados são dinâmicos e muitas vezes múltiplos, isto é, a inter-relação entre os subsistemas faz com que os gargalos surjam em pontos distintos que muitas vezes são apenas identificados indiretamente através de alguma anomalia ou inconformidade em um subsistema posterior. Por exemplo, quando um resultado apresenta uma quantidade de perdas muito grande em uma determinada plataforma, pode-se sugerir que a perda é ocasionada pela falta de embarcação para alívio do petróleo. No entanto, também é possível que cenário esteja com frotas superdimensionadas. Qual seria o gargalo do sistema e como reduzir ou acabar com tais perdas? Neste caso, uma das possibilidades seria que o excesso de embarcações estaria provocando uma longa fila de espera nos pontos de carregamento das plataformas 
e/ou descarregamento dos terminais terrestres, que por sua vez, podem estar obstruindo o atendimento de algum navio de um determinado tipo de petróleo. Da mesma forma, a inexistência de um determinado tipo de petróleo no terminal automaticamente impede que seja cumprida a seqüência de bombeamento, causando uma segunda perda global no bombeamento dos demais tipos de petróleos.

Uma segunda situação bastante comum identificada ao longo do estudo é a grande dificuldade do dimensionamento ideal da capacidade de tancagem dos terminais terrestres. Verificou-se que um simples aumento de capacidade do tanque que abriga um determinado tipo de petróleo em um terminal "A" aumenta a disponibilidade de espaço e conseqüentemente em regime permanente, este terminal consegue uma prioridade de atendimento sobre os demais terminais e, portanto, isto reflete diretamente no dimensionamento da frota e principalmente na necessidade de reestruturar a política de bombeamento dos demais terminais.

As figuras 2 e 3 apresentam os gráficos de nível do tanque em uma plataforma, os níveis dos tanques nos terminais e a distribuição de custos dos navios.

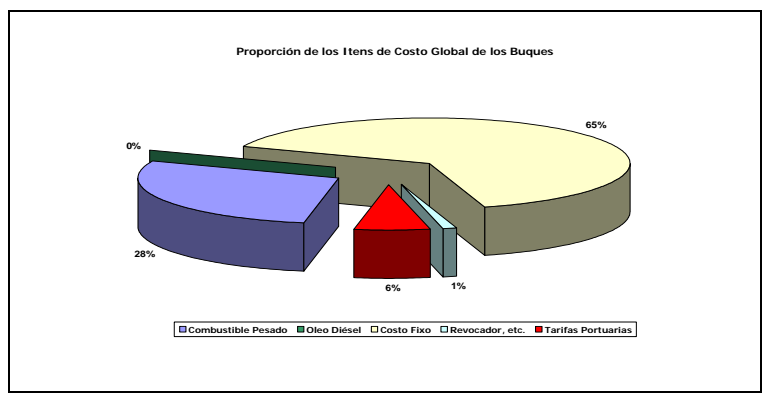

Fig. 2. Distribuição dos custos dos Navios
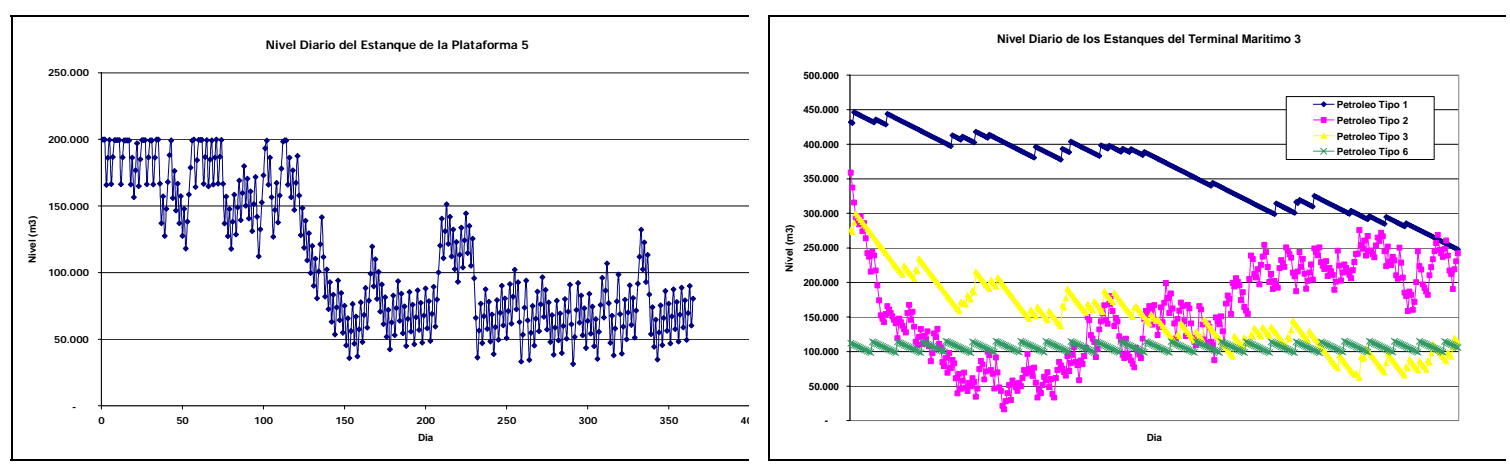

Fig. 3. Comportamentos dos tanques na plataforma e no terminal

A etapa de validação do modelo consistiu em análises de sensibilidade dos principais parâmetros de dimensionamento dos recursos. Foram analisados os resultados dos cenários, com modificações gradativas de aumento ou diminuições de: capacidade dos tanques nas plataformas, posteriormente dos terminais, taxas de bombeamento às refinarias, tamanho e características das frotas, entre outras. $\mathrm{O}$ modelo de simulação permite, dessa forma, avaliar novas políticas de atendimento, testar cenários alternativos e avaliar o impacto que essa alteração provoca em todo o sistema. A figura abaixo mostra um exemplo da análise de dimensionamento dos tanques dos terminais, através do indicador de produtividades. 


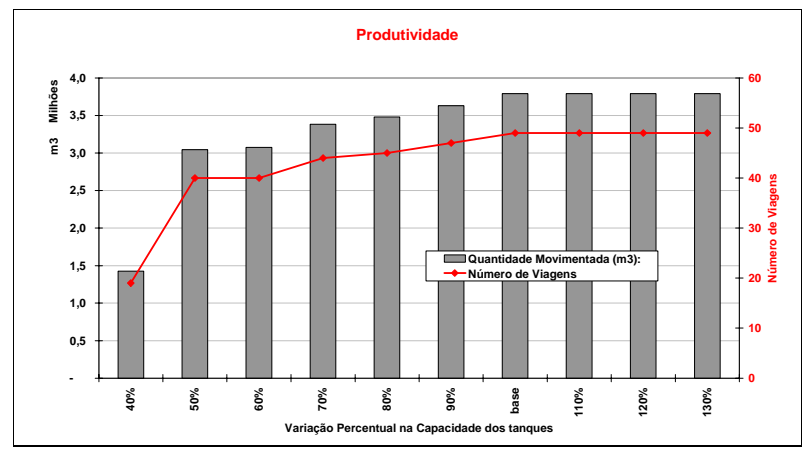

\section{Considerações do modelo de simulação}

A proposta original do presente trabalho, sumariamente, propõe estudar e analisar a cadeia de suprimentos do petróleo, permitindo avaliar e dimensionar adequadamente os recursos envolvidos nos diversos subsistemas, permitir a avaliação de políticas e procedimentos operacionais e finalmente buscar estabelecer os parâmetros limitantes de forma efetiva e consistente.

O modelo de simulação desenvolvido atende aos requisitos propostos integralmente, haja vista a abrangência dos subsistemas modelados e a versatilidade que a técnica de simulação permite, cumpre a tarefa de dimensionamento adequado a cada condição de operação e apresenta os limitantes e os condicionantes do problema. Por outro lado, as políticas para o modelo podem ser testadas através da modificação dos parâmetros.

Contudo, a técnica de simulação, como característica intrínseca, não se propõe a buscar uma boa solução ou uma estratégia eficaz na gestão da cadeia de suprimentos. A construção de um modelo de simulação implica necessariamente na adoção de determinadas regras ou premissas que são consideradas de antemão e que em possíveis situações, as decisões tomadas incorrem em distorções que podem desprezar alternativas de soluções mais plausíveis e realísticas.

O desenvolvimento de um modelo de simulação inclui a adoção da técnica de construção de eventos que servem a uma entidade. Esse modelo tem em sua composição um conjunto de eventos que definem os caminhos em que a entidade deverá cumprir. Naturalmente, existe uma elevada gama de possibilidades e funcionalidades que podem ser atribuídas ao longo desse "caminho" e que permitem a construção do mesmo de forma ilimitada. Contudo, o próprio processo de construção do "caminho" acarreta regras fechadas e definidas a serem atribuídas às entidades, sem a possibilidade de mudanças não previstas inicialmente.

Um exemplo desse condicionante é o fato de que a entidade que percorre um certo tramo do modelo de simulação leva consigo os principais atributos, mas não carrega "em sua memória" as variáveis pelas quais modificou ou modificará ao longo do tramo. A consequêencia imediata e direta é que as decisões tomadas no decorrer da entidade levaram em consideração tão somente fatores associados aos eventos modelados naquele tramo ou em um modelo mais complexo, os principais valores das variáveis globais. Dificilmente, o modelo de simulação tomará a decisão baseada em todas as variáveis envolvidas.

Dessa forma, o detalhamento das operações e a abrangência do enfoque sistêmico atingido pelo modelo de simulação são válidos e extremamente poderosos quando o foco é a validação de determinadas políticas e condições operacionais e, sobretudo, quando buscam a compreensão, a localização e a quantificação dos impactos gerados pelas variáveis que compõem a cadeia de suprimentos.Para que os objetivos inicialmente propostos sejam integralmente cumpridos de forma satisfatória e eficaz, faz-se necessária a complementação do estudo através de uma nova abordagem do problema e que garanta o correto dimensionamento do sistema. Diante do problema exposto, é imperativo que o modelo de simulação integre-se a uma abordagem otimizante, principalmente dos principais subsistemas que compõem a cadeia de suprimentos do petróleo.

\section{O MODELO OTIMIZANTE}

Esta etapa consiste em desenvolver o modelo otimizante, cujo principal objetivo será o de buscar subsídios na formulação do projeto da cadeia de suprimentos do petróleo juntamente com o modelo de 
simulação. Este último mostrou que o sistema modelado apresenta uma alta complexidade na interrelação entre os subsistemas, no que se refere aos parâmetros adotados e, portanto, deverá ser analisada sob o enfoque global, pretendido pelo modelo otimizante.

Ao modelo de simulação, a análise de sensibilidade consistiu em analisar o grau de relevância dos principais parâmetros do modelo; entretanto, os resultados representam tão-somente um caso específico, do cenário analisado. O modelo otimizante proposto deverá estabelecer o projeto da cadeia de suprimentos do petróleo e buscar-se-ão resultados que darão subsídios ao planejamento dessa cadeia. O modelo será tático e, sendo assim, as respostas deverão definir a melhor configuração dos principais recursos do sistema, dentro das restrições estabelecidas.

Dessa forma, o modelo otimizante busca como resultado as condições adequadas ao atendimento da meta estabelecida. Entendem-se como condições adequadas à configuração do sistema logístico da cadeia em termos de quantidades de recursos produtivos e as formas de transferência do petróleo produzido às refinarias. Os fluxos e as condições ótimas de armazenagem deverão nortear a busca pela solução ótima.

O modelo de simulação mostrou que o nível de serviço associado ao sistema modelado está preponderantemente relacionado à oferta de recursos, isto é, na disponibilização de uma frota adequada de navios, tanto em termos de quantidade como de capacidade e também fundamentalmente do dimensionamento correto dos tanques de armazenagem nas plataformas, nos terminais e nas refinarias.

As análises de sensibilidade mostraram que tais recursos definem o escoamento racional sem perdas em todos os subsistemas. Entretanto, o correto dimensionamento está associado à configuração adequada dos recursos e seus respectivos empregos, à combinação das características da frota, à sua alocação e aos níveis de cada um dos tanques. Faz-se necessário ressaltar as diferenças e semelhanças da modelagem proposta ao de AL-KHAYYAL, HWANG (2007), brevemente citado no capítulo referente à revisão bibliográfica. O referido artigo apresenta a modelagem de programação de uma frota de navios graneleiros que efetuam o escoamento de petróleo na região do Pacifico. A modelagem trata um único tipo de variável binária para os arcos, existentes entre os pontos de carregamentos e de descarregamentos, isto é, não considera a possibilidade de efetuar viagens entre pontos de carga e entre pontos de descarga. A consideração da carga também difere pois possibilita a ocupação nos navios por diferentes tipos de produtos, simultaneamente, cerceados pelos porões individuais das embarcações. As atribuições de atracações por nó foram as mesmas utilizada na modelagem proposta; contudo, a consideração de demanda por quantidade de atracações é distinta. No artigo, as demandas são determinadas pelos limites mínimos e máximos dos tanques de armazenagem, diretamente. Tal consideração implica na manipulação dos dados iniciais para que o modelo não resulte na solução básica nula. A introdução da janela de tempo é abordagem inédita na modelagem proposta e não considerada por AL-KHAYYAL. Procedimentos de linearização das restrições que vinculam os arcos são semelhantes.

\section{Descrição do Modelo de Otimização}

O modelo matemático em programação linear, ora proposto consiste na programação de uma frota de navios dedicada à operação de escoamento de petróleo produzido pelas plataformas, a serem transportadas aos terminais na costa, para posterior bombeamento às refinarias.

O conjunto de plataformas de produção que compõem o cenário do sistema analisado produzirá um único tipo de petróleo regido por taxa de produção individual diária e constante. No outro extremo dessa cadeia, existem os terminais, que recebem o petróleo através dos navios e o bombeiam para as refinarias, também sob uma taxa individual diária e constante.

Os roteiros a serem cumpridos pelos navios e as alocações de carga (volumes a serem carregados e descarregados) são as principais variáveis de decisão e que determinarão a melhor programação da frota. Trata-se de um modelo de múltiplas origens e múltiplos destinos, pois tanto o conjunto de plataformas como o conjunto de terminais representam pontos de carga e descarga (origens e destinos).

As decisões inerentes a roteirização dos navios estão condicionadas à manutenção dos níveis dos tanques das plataformas e terminais, cujos limites inferiores e superiores são pré-determinadas.

O modelo deverá encontrar a solução ótima de programação durante o período necessário para cumprimento das atracações pré-determinadas, isto é, a demanda de atendimento às plataformas e terminais serão modeladas de acordo com o número de atracações que deve ocorrer com o lote mínimo de carga /descarga durante o horizonte de planejamento. Como os volumes de carga/descarga poderão ser maiores que os mínimos, os instantes de término das viagens ocorrerão obrigatoriamente posteriores ao instante do horizonte de planejamento. Ou seja, a extensão do período está associada à alocação de carga para cumprimento das atracações pré-determinadas. 
O número de atracações necessárias será calculado em função das taxas (produção para plataformas e bombeamento para terminais), dos estoques iniciais, dos limitantes dos tanques (superiores para plataformas e inferiores para terminais), do lote mínimo de carga/descarga e do horizonte de planejamento. O cálculo consiste em determinar o número de atracações mínimo que deve ocorrer em cada plataforma e terminal, adotando a premissa de lote mínimo para que os níveis dos estoques mantenham-se satisfatórios.

A função objetivo do modelo deverá ser a minimização dos custos relacionados às viagens dos navios a serem realizados.

As variáveis de decisão compreenderão os fluxos entre cada plataforma e cada terminal, por tipo de navio, bem como os tempos associados, os volumes de petróleo carregado e descarregado em cada local e os níveis dos tanques nos terminais e nas plataformas.

\section{O Modelo Conceitual}

O modelo em programação linear mista a ser apresentado envolve um modelo de programação de rotas (scheduling) do serviço de atendimento às plataformas de petróleo. Trata-se, pois, de um modelo com múltiplas origens e múltiplos destinos, servidos por uma frota heterogênea (navios de diferentes capacidades) para escoamento de um único tipo de petróleo, em um horizonte de tempo finito (parâmetro).

As plataformas de produção apresentam tanques que armazenam o petróleo. Sua extração ou produção tende a ocorrer segundo uma taxa de produção constante e são adotadas como parâmetros do modelo. Os terminais têm características semelhantes: possuem seus próprios tanques e o consumo, referente ao bombeamento às refinarias, é simplificado através de uma taxa de consumo, também constante e escolhido como parâmetro do modelo. Cada um dos tanques, nas plataformas e nos terminais, é caracterizado através de parâmetros pelas suas capacidades (limite superior) e limites inferiores. A programação e a alocação das rotas dos navios são realizadas através das atribuições das variáveis binárias, escolhidas segundo a função objetivo de minimização de custos da operação. A designação de rotas é composta por um conjunto de arcos que possibilitam origens e destinos nas plataformas e nos terminais, permitindo também que os navios efetuem viagens entre terminais ou entre plataformas.

A dimensão de tempo no modelo é tratada através da enumeração de seqüência de atracações possíveis no horizonte de tempo pré-estabelecido: para cada ponto de atracação (terminal ou plataforma) e navio, existirá a atribuição de um valor seqüencial que corresponde à ordem de atracação (m ou n). Tal ordem desvincula o tempo dispendido na operação de carga e descarga durante a atracação do navio. Esta abordagem dispensa a discretização temporal e, conseqüentemente provoca uma redução na quantidade de variáveis do modelo. A ordem cronológica é garantida através das restrições de janelas de tempo, em função das seqüências crescentes de atracações. As janelas de tempos serão dinâmicas e calculadas a partir da quantidade de carga carregada nas plataformas e descarregadas nos terminais. Os tempos de viagens de cada navio são considerados como parâmetros do modelo.

As alocações às rotas são efetuadas através de variáveis binárias, que correspondem a arcos entre o terminal de origem e a plataforma de destino, entre a plataforma de origem e o terminal de destino, o terminal de origem e o terminal de destino, ou a plataforma de origem e a plataforma de destino, cada uma, respeitando as seqüências de atracação de cada terminal (m) e plataforma (n), efetuadas pelo navio v. As principais restrições determinam compatibilizar a existência do arco com as operações de carga/descarga, as alocações possíveis segundo as disponibilidades nos porões dos navios e tanques de armazenagem, as janelas de tempos e as restrições de níveis mínimo e máximo de tancagens nos terminais e plataformas.

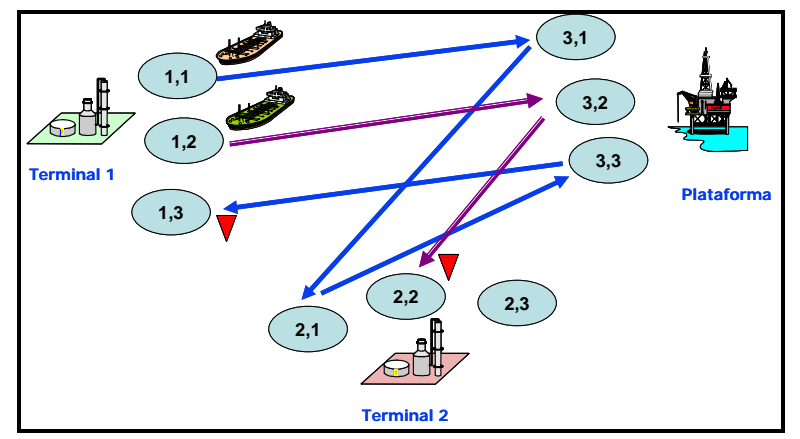

Fig. 4. Exemplo de Configuração Viável 
As alocações às rotas são efetuadas através de variável binária, que corresponde ao arco entre o terminal/plataforma de origem e a plataforma/ terminal de destino, nas seqüências de atracação na origem e no destino, efetuadas pelo navio v.

As principais restrições determinam compatibilizar a existência do arco com as operações de carga/descarga, as alocações possíveis segundo as disponibilidades nos porões dos navios e tanques de armazenagem, as seqüências cronológicas, as restrições de mínimo e máximo níveis de tancagens nos terminais e plataformas.

A decisão de alocação do navio ao ponto de carga ou descarga pressupõe a existência de tanques de armazenagem do tipo de petróleo a ser carregado ou descarregado. Além da necessidade dessa compatibilidade de tipo de petróleo a ser carregado/descarregado pelo navio e a existência do tanque correspondente, existe a restrição do volume a ser transferido, de acordo com as restrições de capacidade do navio e da disponibilidade de espaço nos tanques dos terminais e plataformas. Tal disponibilidade é calculada em função das taxas de produção nas plataformas e das taxas de bombeamento nos terminais. Os limites (inferiores e superiores) são informados ao modelo através de parâmetros.

A figura 4 mostra um exemplo de uma configuração viável em um cenário reduzido, com dois terminais, uma plataforma, dois navios e três possíveis seqüências de atracação em cada terminal e plataforma. As indicações numéricas representam os índices dos locais e índice do número da atracação. Neste exemplo, o primeiro navio inicia a operação com destino ao terminal 1 , na atracação $1(1,1)$. O primeiro arco tem destino na plataforma, na seqüência $1(1,1)$. Em seguida, segue para o terminal 2, na seqüência $1(2,1)$, volta para a plataforma, na seqüência $3(1,3)$, segue novamente para o terminal 1 , na seqüência $3(1,3)$ e encerra a viagem no terminal 2 , na seqüência $3(2,3)$. O segundo navio inicia viagem à plataforma 1 , na seqüência $2(1,2)$, segue ao terminal 1 , na seqüência $2(1,2)$. Em seguida, segue para 0 terminal 2, na seqüência $2(2,2)$, quando termina a viagem.

Cada posição, composta pelo par local-sequência de atracação, deve receber tão- somente uma atracação. A decisão de alocação do navio ao ponto de carga ou descarga pressupõe a disponibilidade de espaços no tanque de armazenagem de petróleo a ser carregado ou descarregado, respeitando-se os limites impostos aos tanques. Tal disponibilidade é calculada em função das taxas de produção nas plataformas e das taxas de consumo (bombeamento) nos terminais e dos limites (inferiores e superiores) calculados pelas janelas de tempo dinâmicas.

As janelas de tempo indicam os instantes máximos em que deve haver uma atracação para que as condições impostas aos tanques sejam respeitadas. Para tanto, a primeira atracação leva em consideração os parâmetros das condições iniciais dos tanques: nível inicial, limites inferiores e superiores, o lote mínimo de carregamento/descarregamento e as taxas de produção/consumo. Com base nos dados referentes às condições iniciais, calcula-se o limite superior de tempo (último instante), isto é, o instante máximo em que a atracação deve ocorrer para que o nível do tanque permaneça dentro dos limites estabelecidos. Nas atracações subseqüentes, os instantes de atracação máximos são calculadas em função do lote de carga carregado/descarregado na atracação anterior e das condições de tanques na atracação anterior.

Com relação à demanda, faz se necessário compreender a atribuição deste atendimento aplicado a esse problema. É necessário que as plataformas tenham condições de produzir o petróleo na taxa de produção indicada durante todo o horizonte de planejamento. Concomitantemente, é necessário que os terminais também tenham condições de bombear o petróleo na taxa de consumo indicada. Assim, o modelo apresenta dois conjuntos de equações, similares, referentes ao atendimento à demanda, para a plataforma e para o terminal.

Para que sejam mantidas e respeitadas as taxas de produção e consumo, é necessário que os volumes de petróleos disponíveis nos tanques permaneçam dentro da faixa estabelecida entre os limites superiores e inferiores dos tanques: para o caso da plataforma, é necessário que ocorram alívios ou descarregamentos aos navios, para a manutenção das taxas de produção; para os terminais, é necessário o recebimento adequado de carga a fim de possibilitar o consumo. Dessa forma, uma das formas de garantir a continuidade é a formulação da restrição de atendimento da demanda através do número de atracações.

O número de atracações que cada plataforma ou terminal deve receber é calculado em função do lote mínimo, que é um parâmetro. O cálculo pressupõe a quantidade de atracações necessárias durante o horizonte de tempo programado, para que os níveis dos tanques permitam a regularidade das taxas de produção e consumo. Após a primeira atracação, a quantidade de petróleo a ser produzida ou consumida até o horizonte de tempo, dividida pelo lote mínimo, resulta na quantidade máxima de atracações necessárias. 


\section{Formulação do Modelo}

\section{Índices}

- $\quad$ i,g...para representar o terminal;

- j,a...para representar a plataforma;

- $\quad m, m^{\prime}$... para representar a ordem da seqüência de atracação no terminal;

- $\quad n, n^{\prime} \ldots$ para representar a ordem da seqüência de atracação na plataforma;

- $\quad$.... para representar o navio;

\section{Conjuntos}

- $V=\{1,2, \ldots, n V\} \ldots$ para representar o conjunto de navios;

- $\quad I=\{1,2, \ldots, n I\} \ldots$ para representar o conjunto de terminais;

- $J=\{1,2, \ldots, n J\} \ldots$ para representar o conjunto de plataformas;

- $\quad M(i)$... para representar o conjunto de atracações no terminal $i$;

- $\quad N(j)$... para representar o conjunto de atracações na plataforma $j$;

\section{Parâmetros}

Os parâmetros utilizados no modelo matemáticos estão descritos a seguir:

Relativos aos custos:

- $C X_{i, j, v} \ldots$ custo em $\mathrm{R} \$$ da viagem do navio de índice $v$, entre o terminal de índice $i$ para a plataforma de índice $j$;

- $C Z_{j, i, v} \ldots$ custo em $\mathrm{R} \$$ da viagem do navio de índice $v$, entre a plataforma de índice $j$ e o terminal de índice $i$;

- $C T E_{g, i, v} \ldots$ custo em $\mathrm{R} \$$ da viagem do navio de índice $v$, entre os terminais de índices $g$ e $i$;

- $\quad C P A_{a, j, v} \ldots$ custo em R $\$$ da viagem do navio de índice $v$, entre as plataformas de índices $a$ e $j$;

- $C O T_{i, v} \ldots$ custo em R $\$$ da viagem inicial do navio de índice $v$, para o terminal de índice $i$;

- $C O P P_{j, v} \ldots$ custo em $\mathrm{R} \$$ da viagem inicial do navio de índice $v$, para a plataforma de índice $j$.

Relativos aos tanques:

- $\quad$ SMNTi ... Nível mínimo do tanque de armazenagem no terminal de índice $i$;

- $\quad S M X T i \ldots$ Nível máximo do tanque de armazenagem no terminal de índice $i$;

- $\quad S M N P j \ldots$ Nível mínimo do tanque de armazenagem na plataforma de índice $j$;

- $\quad S M X P j$... Nível máximo do tanque de armazenagem na plataforma de índice $j$;

- $\quad$ ISTi ... Nível inicial do tanque de armazenagem no terminal de índice $i$;

- $\quad I S P j$... Nível inicial do tanque de armazenagem na plataforma de índice $j$;

- $\quad$ QIv ... Nível inicial do tanque do navio de índice v;

- $\quad C A P v \ldots$ Capacidade do tanque de armazenagem no porão do navio de índice $v$;

- $G$... Maior lote de carga/descarga dentre as capacidades dos tanques de navios, terminais e plataformas;

- $\quad$ QMIN ... Lote mínimo de alívio ou descarregamento.

Relativos às taxas:

- $\quad R P_{j} \ldots$ Taxa de produção na plataforma de índice $j$;

- $\quad R T_{i} \ldots$ Taxa de consumo (bombeio) no terminal de índice $i$;

- $\quad T Q P_{j} \ldots$ Taxa de carregamento na plataforma de índice $j$;

- $\quad T Q T_{i} \ldots$ Taxa de descarregamento no terminal de índice $i$;

Relativos aos tempos:

- $\quad$ T... Horizonte de planejamento para cálculo do número de atracações; 
- $\quad T V G_{i, j, v} \ldots$ Tempo de viagem realizado pelo navio de índice $v$, entre o terminal de índice $i$ e a plataforma de índice $j$ e entre a plataforma de índice $j$ e o terminal de índice $i$;

- $\quad T V G T_{g, i, v} \ldots$ Tempo de viagem realizado pelo navio de índice $v$, entre o terminal de índice $g$ e o terminal de índice $i$;

- $\quad$ TVGP $P_{a, j, v} \ldots$ Tempo de viagem realizado pelo navio de índice $v$, entre a plataforma de índice $a$ e a plataforma de índice $j$;

- $\quad \operatorname{TVGOT}_{, i, v} \ldots$ Tempo de viagem inicial realizado pelo navio de índice $v$, para o terminal de índice $i$;

- $\quad T V G O P_{j, v} \ldots$ Tempo de viagem inicial realizado pelo navio de índice $v$, para a plataforma de índice $j$;

Relativos às atracações:

- $\quad M_{i}=\left\lceil\frac{T^{*} R T_{i}-\left(I S T_{i}-S M N T_{i}\right)}{Q M I N}\right\rceil 1$...Número de atracações no terminal de índice $i$;

- $\quad N_{j}=\left[\frac{T^{*} R P_{j}-\left(S M X P_{j}-I S P_{j}\right)}{Q M I N}\right] 2$...Número de atracações na plataforma de índice $j$;

\section{Variáveis de Decisão}

Relativos ao sistema global: $C^{T}$... custo total;

Relativos ao fluxo:

- $X_{\text {imjnv }}:=1$, se o navio $v$ fizer a atracação de ordem $m$ no terminal $i$ e seguir para a plataforma $j$ onde fará a atracação de ordem $n$;

... 0, caso contrário;

- $Z_{\text {jnimv }}:=1$, se o navio $v$ fizer a atracação de ordem $n$ na plataforma $j$ e seguir para o terminal $i$ onde fará a atracação de ordem $m$;

$:=0$, caso contrário;

- $\quad W_{\text {gm }{ }^{\prime} i m v}:=1$, se o navio $v$ fizer a atracação de ordem $m^{\prime}$ no terminal $g$ e seguir para outro terminal $i$ onde fará a atracação de ordem $m$;

$:=0$, caso contrário;

- $U_{a n^{\prime} j n v}:=1$, se o navio $v$ fizer a atracação de ordem $n^{\prime}$ na plataforma $a$ e seguir para outra plataforma $j$ onde fará a atracação de ordem $n$;

$:=0$, caso contrário;

- $V I T_{i m v}:=1$, se o navio $v$ fizer a viagem de início para o terminal $i$, na atracação de ordem $m$; $:=0$, caso contrário;

- $V I P_{i n v}:=1$, se o navio $v$ fizer a viagem de início para a plataforma $j$, na atracação de ordem $n$; $:=0$, caso contrário;

- $V_{F T} T_{i m v}:=1$, se o navio $v$ fizer a viagem final de conclusão a partir do terminal $i$, na atracação de ordem $m$; $:=0$, caso contrário;

- $V F P_{j n v}:=1$, se o navio $v$ fizer a viagem final de conclusão a partir da plataforma $j$, na atracação de ordem $n$;

$:=0$, caso contrário;

- $Y_{v}:=1$, se o navio $v$ não fizer nenhuma viagem; $:=0$, caso contrário;

Relativos à operações de carga/descarga:

- $q T_{i m} \ldots$ volume de carga descarregado no terminal de índice $i$, na atracação de ordem $m$;

- $q P_{j n} . .$. volume de carga carregado na plataforma de índice $j$, na atracação de ordem $n$;

- $\quad I T_{i m v} . .$. volume de petróleo presente no tanque do navio de índice $v$ na saída da atracação de ordem $m$, no terminal de índice $i$;

${ }^{12}$ Notação $\lceil$ devolve o valor do maior número inteiro 
- $l P_{j n v} \ldots$ volume de petróleo presente no tanque do navio de índice $v$ na saída da atracação de ordem $n$, na plataforma de índice $j$;

Relativos ao tempo:

- $t T_{\text {im }} \ldots$ instante de tempo da atracação de ordem $m$, no terminal de índice $i$;

- $t P_{j n} \ldots$ instante de tempo da atracação de ordem $n$, na plataforma de índice $j$;

- $l s T_{i m} \ldots$... limite superior da janela de tempo para atracação de ordem $m$, no terminal de índice $i$;

- $l s P_{j n} \ldots$ limite superior da janela de tempo para atracação de ordem $n$, na plataforma de índice $j$;

Relativos às tancagens:

- $s T_{i m} \ldots$ nível do tanque do terminal de índice $i$, no instante inicial da atracação de ordem $m$;

- $s P_{j n} \ldots$ nível do tanque da plataforma de índice $j$, no instante inicial da atracação de ordem $n$;

\section{Função Objetivo}

A função objetivo é minimizar o custo total das viagens realizadas pela frota de navios. Estão incluídos todos os arcos possíveis:

- $\quad$ Entre terminais e plataformas $\left(X_{\text {imjnv }}\right)$ e o arco inverso $\left(Z_{\text {jnimv }}\right)$;

- $\quad$ Entre terminais $\left(W_{\text {gm }}{ }^{\prime} i m v\right)$;

- Entre plataformas $\left(U_{a n j n v}\right)$ e

- Viagens iniciais para plataformas e terminais $\left(V I P_{j n v}\right.$ e $\left.V I T_{i m v}\right)$.

A equação desta função objetivo é apresentada abaixo:

$$
\begin{aligned}
& C T=\sum_{i \in I} \sum_{m \in M(i)} \sum_{j \in J} \sum_{n \in N(j)} \sum_{v \in V} C X_{i j v} X_{i m j n v}+\sum_{i \in I} \sum_{m \in M(i)} \sum_{j \in J} \sum_{j \in N(j)} \sum_{n \in V} C Z_{j i v} Z_{j n i m v}+ \\
& \sum_{g \in I} \sum_{m^{\prime} \in M(g)} \sum_{i \in I} \sum_{m \in M(i)} \sum_{v \in V} C T E_{g i v} W_{g m^{\prime} i m v}+\sum_{a \in J} \sum_{n^{\prime} \in N(a)} \sum_{j \in J} \sum_{n \in N(j)} \sum_{v \in V} C P A_{a j v} U_{a n^{\prime} j n v}+ \\
& \sum_{i \in I} \sum_{m \in M(i)} \sum_{v \in V} C 0 T_{i v} V I T_{i m v}+\sum_{j \in J} \sum_{n \in N(j)} \sum_{v \in V} C 0 P_{j v} V I P_{j n v}
\end{aligned}
$$

\section{Restrições}

As restrições foram subdivididas nas seguintes categorias:

- Relativas ao fluxo: conjunto de restrições que criam um único arco de início por navio e, a partir delas, garantem a continuidade dos mesmos até a realização da viagem final.

- Relativas aos atendimentos nas plataformas e terminais: conjunto de restrições que estabelecem os volumes de carga a serem carregados ou descarregados, respeitando-se os lotes mínimos e máximos. Além destas, estabelece a demanda nos terminais e nas plataformas, em função das quantidades de atracações pré-determinadas.

- Relativas às janelas de tempos: conjunto de restrições que calculam os limites superiores das janelas de tempo, em função das características dos níveis de tanques.

- Relativas aos tempos: instantes de atracações nas plataformas e terminais que são estabelecidos, oriundos de todas as possíveis condições de origens e estabelecem as ordens crescentes das atracações.

- Relativas às tancagens nos terminais e plataformas: conjunto de restrições que calculam os valores dos níveis dos tanques nas plataformas e terminais, estabelecendo-os dentro dos limites estabelecidos.

- Relativa às tancagens nos navios: conjunto de restrições que definem o volume de tanque nos porões dos navios, após as atracações, condicionando-os com as existências dos arcos e aos limites da capacidade dos navios.

- Relativa às não negatividades das variáveis binárias e reais. 


\section{Relativos ao fluxo}

- $\quad$ Condição Inicial dos navios:

$\sum_{i} \sum_{m \in M(i)} V I T_{i m v}+\sum_{j} \sum_{n \in N(j)} V I P_{j n v}+Y_{v}=1 \quad, \forall v \in V$

A expressão 1 garante que cada navio aloque um único arco de início, seja por uma plataforma $\left(V I P_{j n v}\right)$, pelo terminal $\left(V I T_{i m v}\right)$ ou não aloque nenhuma viagem $\left(Y_{v}\right)$. Caso esta última variável seja selecionada, não haverá nenhum outro arco intermediário até a encerramento.

- No máximo um arco de saída de cada plataforma com destino a algum terminal ou alguma plataforma:

$\sum_{i} \sum_{m \in M(i)} \sum_{v} Z_{j n i m v}+\sum_{a} \sum_{n^{\prime} \in N(a)} \sum_{v} U_{j n a n^{\prime} v} \leq 1 \quad \forall j \in J, \forall n \in N(j)$

A expressão 2 garante que para qualquer plataforma $(j)$ e qualquer seqüência de atracação $(n)$, exista no máximo um único arco com destino a algum terminal ou alguma plataforma.

- $\quad$ No máximo um arco de saída de cada terminal com destino a alguma plataforma ou algum terminal:

$$
\sum_{j} \sum_{n \in N(j)} \sum_{v} X_{i m j n v}+\sum_{g} \sum_{m^{\prime} \in M(g)} \sum_{v} W_{i m g m^{\prime} v} \leq 1 \quad \forall i \in I, \forall m \in M(i)
$$

A expressão 3 garante que para qualquer terminal $(i)$ e qualquer seqüência de atracação $(m)$, exista no máximo um único arco com destino a alguma plataforma ou algum terminal.

- $\quad$ Continuidade na plataforma:

$\sum_{i} \sum_{m \in M(i)} X_{i m j n v}+\sum_{a} \sum_{n^{\prime} \in N(a)} U_{a n^{\prime} j n v}+V I P_{j n v}-$

$\sum_{i} \sum_{m \in M(i)} Z_{j n i m v}-\sum_{a} \sum_{n^{\prime} \in N(a)} U_{j n a n^{\prime} v}-V F P_{j n v}=0$

$\forall j \in J, \forall n \in N(j), \forall v \in V$

A expressão 4 estabelece a continuidade dos arcos na plataforma $(j)$ e atracação (n). Os fluxos de chegada são os oriundos de terminais $\left(X_{\text {imjnv }}\right)$, oriundos de outras plataformas $\left(U_{a n ' j n v}\right)$ ou oriundos da condição inicial $\left(V I P_{j n v}\right)$. Os fluxos de saída são os de destino para um dos terminais $\left(Z_{j n i m v}\right)$, destino para uma das plataformas $\left(U_{\text {jnan'v }}\right)$ ou destino de arco final $\left(V F P_{j n v}\right)$.

- $\quad$ Continuidade no terminal:

$\sum_{j} \sum_{n \in N(j)} Z_{j n i m v}+\sum_{g} \sum_{m^{\prime} \in M(g)} W_{g m^{\prime} i m v}+V I T_{i m v}-$

$\sum_{j} \sum_{n \in N(j)} X_{i m j n v}-\sum_{g} \sum_{m^{\prime} \in M(g)} W_{i m g m^{\prime} v}-V F T_{i m v}=0$

$\forall i \in I, \forall m \in M(i), \forall v \in V$

A expressão 5 estabelece a continuidade dos arcos no terminal $(i)$ e atracação $(m)$. Os fluxos de chegada são os oriundos de plataformas $\left(Z_{\text {jnimv }}\right)$, oriundos de outros terminais $\left(W_{g m^{\prime} i m v}\right)$ ou oriundos da condição inicial $\left(V I T_{i m v}\right)$. Os fluxos de saída são os de destino para uma das plataformas $\left(X_{i m j n v}\right)$, destino para um dos terminais $\left(W_{\text {imgm'v }}\right)$ ou destino de arco final $\left(V F T_{i m v}\right)$.

- Condição Final dos navios:

$\sum_{i} \sum_{m \in M(i)} V F T_{i m v}+\sum_{j} \sum_{n \in N(j)} V F P_{j n v}+Y_{v}=1 \quad \forall v \in V$

A expressão 6 garante que cada navio $v$ termine a missão em uma única posição: no terminal $i$ e atracação $m$, na plataforma $j$ e atracação $n$ ou na condição inicial, sem viagens. 


\section{Relativos aos atendimentos nas plataformas e terminais}

- $\quad$ Lote mínimo no alívio da plataforma:

$q P_{j n} \geq Q \operatorname{MIN}\left(\sum_{i} \sum_{m \in M(i)} \sum_{v} X_{i m j n v}+\sum_{a} \sum_{n^{\prime} \in N(a)} \sum_{v} U_{a n^{\prime} j n v}+\sum_{v} V I P_{j n v}\right)$

$\forall j \in J, \forall n \in N(j)$

- $\quad$ Lote mínimo no descarregamento do terminal:

$q T_{i m} \geq Q M I N\left(\sum_{j} \sum_{n \in N(j)} \sum_{v} Z_{j n i m v}+\sum_{g} \sum_{m^{\prime} \in M(g)} \sum_{v} W_{g m^{\prime} i m v}+\sum_{v} V I T_{i m v}\right)$

$\forall i \in I, \forall m \in M(i)$

As expressões 7 e 8 estabelecem o lote mínimo, definido como parâmetro para carregamento na plataforma e descarregamento no terminal, condicionadas às existências de seus respectivos arcos. $\mathrm{O}$ valor deve ser respeitado como condição para garantir a demanda do número de atracações previstas para cada terminal e plataforma, calculados segundo condições iniciais dos níveis mínimos e máximos dos tanques.

- $\quad$ Lote máximo no alívio da plataforma:

$$
\begin{aligned}
& q P_{j n} \leq I S P_{j}+t P_{j n}^{*} R P_{j}-S M N P_{j} \quad \forall j \in J, \forall n \in N(j): n=1 \\
& q P_{j n} \leq s P_{j n-1}-q P_{j n-1}+\left(t P_{j n}-t P_{j n-1}\right) * R P_{j}-S M N P_{j} \quad \forall j \in J, \forall n \in N(j): n>1
\end{aligned}
$$

As expressões 9 e 10 calculam os volumes a serem carregados na plataforma. A expressão 9 é atribuída à condição inicial, cujo volume a ser carregado não deve ultrapassar o volume inicial disponível, somado ao volume produzido até o momento da atracação e subtraído do volume equivalente ao limite inferior do tanque. A expressão 10 recalcula os volumes a serem carregados, a partir da segunda atracação, quando são considerados os níveis de estoques na atracação anterior, subtraído da parcela do volume carregado no início da atracação anterior, somado ao volume produzido durante o intervalo de tempo entre as atracações e finalmente, subtraído do limite inferior do tanque.

- $\quad$ Lote máximo no alívio do terminal:

$$
\begin{aligned}
& q T_{i m} \leq S M X T_{i}-\left(I S T_{i}-t T_{i m} * R T_{i}\right) \quad \forall i \in I, \forall m \in M(i): m=1 \\
& q T_{i m} \leq S M X T_{i}-\left(s T_{i m-1}+q T_{i m-1}-\left(t T_{i m}-t T_{i m-1}\right) * R T_{i}\right) \\
& \forall i \in I, \forall m \in M(i): m>1
\end{aligned}
$$

As expressões 11 e 12 calculam os volumes a serem descarregados no terminal. A expressão 11 é atribuída à condição inicial, cujo volume a ser descarregado não deve ultrapassar o volume equivalente ao estoque máximo, subtraído do volume inicial disponível e do volume bombeado (consumido) até o momento da atracação. A expressão 12 recalcula os volumes a serem descarregados a partir da segunda atracação, que equivale ao estoque máximo subtraído do nível na atracação anterior, do volume descarregado na atracação anterior e do volume bombeado durante o intervalo de tempo entre as atracações.

- $\quad$ Lote de alívio na plataforma, condicionada à existência do arco de início à plataforma, do arco entre plataformas e do arco do terminal para a plataforma:

$$
\begin{aligned}
& q P_{j n} \leq\left(\sum_{i} \sum_{m \in M(i)} \sum_{v} X_{i m j n v}+\sum_{a} \sum_{n^{\prime} \in N(a)} \sum_{v} U_{a n^{\prime} j n v}+\sum_{v} V I P_{j n v}\right) * G \\
& \forall j \in J, \forall n \in N(j)
\end{aligned}
$$

- $\quad$ Lote de descarga do terminal, condicionada à existência do arco de início ao terminal, do arco entre terminais e do arco da plataforma ao terminal: 


$$
q T_{i m} \leq\left(\sum_{j} \sum_{n \in N(j)} \sum_{v} Z_{j n i m v}+\sum_{g} \sum_{m^{\prime} \in M(g)} \sum_{v} W_{g m^{\prime} i m v}+\sum_{v} V I T_{i m v}\right)^{*} G
$$

$\forall i \in I, \forall m \in M(i)$

As expressões 13 e 14 têm funções de condicionarem a existência dos lotes de carregamento ou descarregamento à existência do arco que originará a atracação.

- $\quad$ Atendimento de Demanda nas Plataformas:

$$
\sum_{i} \sum_{m \in M(i)} \sum_{v} X_{i m j n v}+\sum_{a} \sum_{n^{\prime} \in N(a)} \sum_{v} U_{a n^{\prime} j n v}+\sum_{v} V I P_{j n v}=1 \quad \forall j \in J, \forall n \in N(j)
$$

- $\quad$ Atendimento de Demanda nos Terminais:

$$
\sum_{j} \sum_{n \in N(j)} \sum_{v} Z_{j n i m v}+\sum_{g} \sum_{m^{\prime} \in M(g)} \sum_{v} W_{g m^{\prime} i m v}+\sum_{v} V I T_{i m v}=1 \quad \forall i \in I, \forall m \in M(i)
$$

As expressões 15 e 16 consistem em restrições que estabelecem a obrigatoriedade de existência das atracações. De forma indireta, pode-se denominar como sendo de atendimento às demandas. $\mathrm{O}$ cálculo do número de atracações de cada terminal ou plataforma levou em consideração o cumprimento dos limites inferiores e superiores dos tanques, através dos intervalos de tempos mínimos e máximos para um lote de carga mínimo, de forma a respeitar as condições impostas.

- $\quad$ Tempo de Operação da atracação de índice $m$, no terminal de índice $i$ :

$$
p T_{i m}=q T_{i m} / T Q T_{i} \quad \forall i \in I, \forall m \in M(i)
$$

- $\quad$ Tempo de Operação da atracação de índice $n$, na plataforma de índice $j$ :

$$
p P_{j n}=q P_{j n} / T Q P_{j} \quad \forall j \in J, \forall n \in N(j)
$$

As expressões 17 e 18 estabelecem os tempos de operação nos terminais e nas plataformas, calculadas em função do lote a ser descarregado ou carregado, divididos pelas taxas de descarregamento e carregamento.

\section{Relativos a Janela de Tempo}

- $\quad$ Limite superior da janela de tempo na plataforma de índice $j$, na atracação de índice $n$ :

$$
\begin{array}{ll}
l s P_{j n}=\frac{S M X P_{j}-I S P_{j}}{R P_{j}} & \forall j \in J, \forall n \in N(j): n=1 \\
l s P_{j n}=t P_{j n-1}+\frac{S M X P_{j}-\left(s P_{j n-1}-q P_{j n-1}\right)}{R P_{j}} & \forall j \in J, \forall n \in N(j): n>1
\end{array}
$$

As expressões 19 e 20 determinam os limites superiores das atracações nas plataformas. Para a primeira atracação, a equação 19 calcula o intervalo de tempo decorrido até que o nível do tanque atinja o limite superior. Para as demais atracações, esse tempo é calculado em função das condições da atracação anterior: instante, nível do tanque e volume aliviado.

- $\quad$ Limite superior da janela de tempo no terminal de índice $i$, na atracação de índice $m$ :

$$
\begin{array}{ll}
l s T_{i m}=\frac{I S T_{i}-S M N T_{i}}{R T_{i}} & \forall i \in I, \forall m \in M(i): m=1 \\
l s T_{i m}=t T_{i m-1}+\frac{s T_{i m-1}+q T_{i m-1}-S M N T_{i}}{R T_{i}} & \forall i \in I, \forall m \in M(i): m>1
\end{array}
$$


As expressões 21 e 22 são análogas às duas anteriores e determinam os limites superiores dos instantes das atracações nos terminais. O limitante superior do instante de atracação para o terminal é ditado pelo nível mínimo do tanque, pois o terminal consome o petróleo e portanto, o nível do tanque diminui. Para a primeira atracação, a equação 21 calcula o intervalo de tempo decorrido até que o nível do tanque atinja o limite inferior. Para as demais atracações, esse tempo é calculado em função das condições da atracação anterior: instante, nível do tanque e volume descarregado.

- Imposição do limite superior da janela de tempo no terminal de índice $i$, na atracação de índice $m:$

$$
t T_{i m} \leq l s T_{i m} \quad \forall i \in I, \forall m \in M(i)
$$

- Imposição do limite superior da janela de tempo na plataforma de índice $j$, na atracação de índice n:

$$
t P_{j n} \leq l s P_{j n} \quad \forall j \in J, \forall n \in N(j)
$$

As expressões 23 e 24 completam o conjunto de restrições das janelas de tempos, estabelecendo os instantes de atracações máximos a serem atendidos até os limites superiores calculados.

\section{Relativos a Tempo}

- Instante de atracação na plataforma, para um navio vindo da condição inicial: $t P_{j n} \geq T V G 0 P_{j v}-\left(1-V_{j n v}\right) * T \quad, \forall j \in J, \forall n \in N(j), \forall v \in V$

- Instante de atracação na plataforma, para um navio vindo de um terminal: $t P_{j n} \geq t T_{i m}+p T_{i m}+T V G_{i j v}-\left(1-X_{i m j n v}\right) * T$

$\forall j \in J, \forall n \in N(j), \forall i \in I, \forall m \in M(i), \forall v \in V$

- $\quad$ Instante de atracação na plataforma, para um navio vindo de uma outra plataforma:

$$
\begin{aligned}
& t P_{j n} \geq t P_{a n^{\prime}}+p P_{a n^{\prime}}+T V G_{a j v}-\left(1-U_{a n^{\prime} j n v}\right) * T \\
& \forall j \in J, \forall n \in N(j), \forall a \in J, \forall n^{\prime} \in N(a), \forall v \in V
\end{aligned}
$$

As expressões 25, 26 e 27 alocam os tempos associados à viagem e atendimento, aos instantes de atracação, condicionados à existência dos arcos. A expressão 25 considera somente o tempo de viagem para chegada à plataforma, quando a variável $V I P_{j n v}$ for selecionada. A expressão 26 considera o tempo de viagem do terminal de índice $i$ e atracação de índice $m$ para a plataforma de índice $j$ e atracação de índice $n$, o instante da atracação de índice $m$, o tempo de atendimento no terminal, todos condicionados à existência do arco $X_{\text {imjnv }}$. A expressão 27 é análoga à anterior, considerando que a origem do arco é uma outra plataforma.

- $\quad$ Seqüência de atracações na plataforma:

$$
t P_{j n} \geq t P_{j n-1}+p P_{j n-1} \quad \forall j \in J, \forall n \in N(j): n>1
$$

A expressão 28 reforça a necessidade da ordenação crescente das atracações ao longo do tempo e garante que o início de uma atracação ocorra somente após o tempo de atendimento da atracação anterior. Isto porque, existe a possibilidade de haver atracações consecutivas para um mesmo terminal ou plataforma.

- Instante de atracação no terminal, vindo da condição inicial:

$t T_{i m} \geq T V G 0 T_{i v}-\left(1-V I T_{i m v}\right) * T \quad, \forall i \in I, \forall m \in M(i), \forall v \in V$

- Instante de atracação no terminal, vindo de uma plataforma:

$t T_{i m} \geq t P_{j n}+p P_{j n}+T V G_{i j v}-\left(1-Z_{j n i m v}\right) * T$

$\forall j \in J, \forall n \in N(j), \forall i \in I, \forall m \in M(i), \forall v \in V$ 
- Instante de atracação no terminal, vindo de um outro terminal: $t T_{i m} \geq t T_{g m^{\prime}}+p T_{g m^{\prime}}+T V G_{g i v}-\left(1-W_{g m^{\prime} i m v}\right) * T$

$\forall g \in I, \forall m^{\prime} \in M(g), \forall i \in I, \forall m \in M(i), \forall v \in V$

As equações 29 a 31 são análogas às equações 25 a 27, destinadas aos terminais.

- $\quad$ Seqüência de atracações no terminal:

$t T_{i m} \geq t T_{i m-1}+p T_{i m-1} \quad \forall i \in I, \forall m \in M(i): m>1$

\section{Relativos as Tancagens nos Terminais e Plataformas}

- $\quad$ Estoque mínimo em cada plataforma de índice $j$ no início de cada atracação:

$$
s P_{j n} \geq S M N P_{j} \quad \forall j \in J, n \in N(j)
$$

- $\quad$ Estoque mínimo em cada terminal de índice $i$ no início de cada atracação:

$$
s T_{i m} \geq S M N T_{i} \quad \forall i \in I, m \in M(i)
$$

- $\quad$ Estoque na plataforma de índice $j$, no início da atracação $n$ :

$$
\begin{aligned}
& s P_{j n}=I S P_{j}+t P_{j n}^{*} R P_{j} \quad \forall j \in J, n \in N(j): n=1 \\
& s P_{j n}=s P_{j n-1}-q P_{j n-1}+\left(t P_{j n}-t P_{j n-1}\right) * R P_{j} \quad \forall j \in J, n \in N(j): n>1
\end{aligned}
$$

As expressões 35 e 36 calculam os valores dos níveis de tanques no início de cada atracação. Para a primeira atracação, consideram-se as condições iniciais. Para as demais, consideram-se as condições da atracação anterior: nível do tanque, o volume aliviado pelo navio e volume produzido no intervalo de tempo entre as atracações.

- $\quad$ Estoque no terminal de índice $i$, no início da atracação $m$

$$
\begin{aligned}
& s T_{i m}=I S T_{i}-t T_{i m}^{*} R T_{i} \quad, \forall i \in I, m \in M(i): m=1 \\
& s T_{i m}=s T_{i m-1}+q T_{i m-1}-\left(t T_{i m}-t T_{i m-1}\right) * R T_{i} \quad \forall i \in I, m \in M(i): m>1
\end{aligned}
$$

As equações 37 e 38 são análogas às anteriores, aplicadas aos terminais.

\section{Relativos à tancagens nos navios}

- $\quad$ Volume de petróleo no porão do navio $v$, após a atracação de ordem $n$, na plataforma $j$ :

$$
\begin{aligned}
& V I P_{j n v}\left[Q I+q P_{j n}-l P_{j n v}\right]=0, \forall j \in J, \forall n \in N(j): n=1, \forall v \in V \\
& X_{i m j n v}\left[I T_{i m v}+q P_{j n}-l P_{j n v}\right]=0, \forall i \in I, \forall m \in M(i), \forall j \in J, \forall n \in N(j), \forall v \in V \\
& U_{a n^{\prime} j n v}\left[I P_{a n^{\prime} v}+q P_{j n}-I P_{j n v}\right]=0, \forall a \in J, \forall n^{\prime} \in N(a), \forall j \in J, \forall n \in N(j), \forall v \in V
\end{aligned}
$$

As equações 39, 40 e 41 determinam os valores dos volumes nos porões dos navios na saída do atendimento da plataforma de índice $j$, na atracação de índice $n$. As equações estão condicionadas aos arcos de viagem inicial, para a primeira atracação, arcos oriundos de terminais e arcos oriundos de outras plataformas, respectivamente. As equações são não lineares e, portanto, devem ser transformadas em equações lineares.

A linearização é feita através da reformulação das equações para um conjunto de equações inteiromistas equivalentes, segundo Sherali, H.D. (1998), que explicita a estrutura de um problema não linear, delimitada pela região viável da seguinte forma:

$$
\{(x, y) \mid x f(y)=0, x \in\{0,1\}, y \in Y\}
$$


onde $f(y)$ é a função de domínio $Y$. Para o caso específico, tomando como exemplo, a equação 41, é possível adotar $x$ como sendo a variável binária $V I P_{j n v}$ e $y$ como $\left(q P_{j n}, I P_{j n v}\right)$ e $f(y)$ como sendo $Q I_{v}+q P_{j n}-I P_{j n v}$.

Considerando o conjunto $T=\{(x, y) \mid x f(y)=0, x \in\{0,1\}, y \in Y\}$, onde $\{f(y) \mid y \in Y\}$, é compacto, isto é, que existam limites inferiores e superiores[I,S] que satisfazem:

$$
I \leq f(y) \leq S, y \in Y
$$

Então, o conjunto $T$ é equivalente a

$$
T^{\prime}=\{(x, y) \mid I(1-x) \leq f(y) \leq S(1-x), x \in\{0,1\}, y \in Y\} .
$$

A função $f(y)=Q I_{v}+q P_{j n}-I P_{j n v}$ é linear e os parâmetros $-G$ e G são válidos como limites inferiores e superiores, respectivamente. Utilizando a proposição resultante da linearização, dada por $T$ 'da demonstração anterior e substituindo as variáveis, tem-se:

$$
\begin{array}{ll}
I P_{j n v} \geq Q I_{v}+q P_{j n}-\left(1-V I P_{j n v}\right) * G & \forall j \in J, \forall n \in N(j): n=1, \forall v \in V \\
I P_{j n v} \leq Q I_{v}+q P_{j n}+\left(1-V I P_{j n v}\right) * G & \forall j \in J, \forall n \in N(j): n=1, \forall v \in V
\end{array}
$$

De forma análoga, tem-se as demais equações aplicadas aos outros dois arcos binários:

$$
\begin{aligned}
& l P_{j n v} \geq I T_{i m v}+q P_{j n}-\left(1-X_{i m j n v}\right) * G \\
& \forall i \in I, \forall m \in M(i), \forall j \in J, \forall n \in N(j), \forall v \in V \\
& l P_{j n v} \leq I T_{i m v}+q P_{j n}+\left(1-X_{i m j n v}\right) * G \\
& \forall i \in I, \forall m \in M(i), \forall j \in J, \forall n \in N(j), \forall v \in V \\
& l P_{j n v} \geq I P_{a n^{\prime} v}+q P_{j n}-\left(1-U_{a n^{\prime} j n v}\right) * G \\
& \forall a \in I, \forall n^{\prime} \in N^{\prime}(a), \forall j \in J, \forall n \in N(j), \forall v \in V \\
& l P_{j n v} \leq l P_{a n^{\prime} v}+q P_{j n}+\left(1-U_{a n^{\prime} j n v}\right) * G \\
& \forall a \in I, \forall n^{\prime} \in N^{\prime}(a), \forall j \in J, \forall n \in N(j), \forall v \in V
\end{aligned}
$$

- Volume de petróleo no tanque do navio $v$, após a atracação de ordem $m$, no terminal $i$ :

Analogamente ao apresentado para cálculo dos estoques na plataforma, a mesma estrutura pode ser aplicada para o caso dos estoques do navio na saída do terminal, tendo assim:

$$
\begin{aligned}
& I T_{i m v} \geq Q I_{v}+q T_{i m}-\left(1-V I T_{i m v}\right) * G \quad, \forall i \in I, \forall m \in M(i), \forall v \in V \\
& I T_{i m v} \leq Q I_{v}+q T_{i m}+\left(1-V I T_{i m v}\right) * G \\
& \forall i \in I, \forall m \in M(i), \forall v \in V \\
& I T_{i m v} \geq I P_{j n v}-q T_{j n}-\left(1-Z_{j n i m v}\right) * G \\
& \forall i \in I, \forall m \in M(i), \forall j \in J, \forall n \in N(j), \forall v \in V \\
& I T_{i m v} \leq I P_{j n v}-q T_{j n}+\left(1-Z_{j n i m v}\right) * G \\
& \forall i \in I, \forall m \in M(i), \forall j \in J, \forall n \in N(j), \forall v \in V \\
& I T_{i m v} \geq I T_{g m^{\prime} v}-q T_{i m}-\left(1-W_{g m^{\prime} i m v}\right) * G \\
& \forall g \in I, \forall m^{\prime} \in M(g), \forall i \in I, \forall m \in M(i), \forall v \in V
\end{aligned}
$$


$I T_{i m v} \leq I T_{g m^{\prime} v}-q T_{i m}+\left(1-W_{g m^{\prime} i m v}\right) * \mathrm{G}$

$\forall g \in I, \forall m^{\prime} \in M(g), \forall i \in I, \forall m \in M(i), \forall v \in V$

- $\quad$ Estoque máximo do navio na saída da plataforma:

$l P_{j n v} \leq C A P_{v} \quad, \forall j \in J, \forall n \in N(j), \forall v \in V$

- $\quad$ Estoque máximo do navio na saída do terminal:

$l T_{i m v} \leq C A P_{v} \quad, \forall i \in I, \forall m \in M(i), \forall v \in V$

As expressões 45 e 46 limitam a quantidade de carga presente no navio até a sua capacidade.

\section{Não negatividade das variáveis}

- $\quad$ Binárias: $X_{i m j n v}, Z_{j n i m v}, W_{g m^{\prime} i m v}, U_{a n^{\prime} j n v}, V I P_{j n v}, V I T_{i m v}, Y_{v}, V F P_{j n v}, V F T_{i m v}$;

- $\quad$ Reais: $q T_{i m}, q P_{j n}, l T_{\mathrm{imv}}, l P_{\mathrm{jnv}}, t T_{i m}, t P_{j n}, l s T_{i m}, l s P_{j n}, s T_{i m}, s P_{j n .}$

\section{Implementação Computacional e Resultados}

O modelo de otimização foi desenvolvido em programação linear mista e a implementação computacional em linguagem matemática C++ e VBA. A formulação do modelo causou a elevada quantidade de classes de restrições e a adoção de grande quantidade de variáveis binárias, principalmente as relacionadas aos arcos, que contêm preponderantemente cinco índices. O porte do modelo e o possível potencial de dificuldades na execução foram determinantes para a seleção do pacote computacional a ser utilizado na implementação. Estão ao alcance do autor, duas grandes ferramentas de resolução de problemas em programação linear: o software GAMS, sistema geral de modelagem algébrica, na versão 20.0, cujo algoritmo de resolução utiliza o CPLEX, na versão 7.0, e a utilização direta do algoritmo CPLEX, na versão 10.0.

A implementação no CPLEX 10.0 requer a criação do modelo matemático em linguagem C++, cujas rotinas de leitura de dados, leitura das equações, execução e apresentação dos resultados são padronizadas, o que facilita demasiadamente sua criação. A geração do modelo foi feita utilizando-se os recursos do Microsoft Excel, sobretudo através da criação de Macros em linguagem VBA. Os parâmetros foram definidos em planilhas de acordo com as categorias de dados e, através das rotinas em VBA, criados os conjuntos de equações do modelo. Dessa forma, a geração de cenários, com modificação de alguma característica dos parâmetros do modelo é feita através do próprio Microsoft Excel. Os computadores utilizados para execução dos modelos possuem processadores Pentium IV, 1,7 Ghz, 512 MB de memória RAM e 40GB de HD.

\section{Resultados - Cenário hipotético}

Com o intuito de testar e validar as respostas do modelo, bem como avaliar o esforço computacional e o grau de otimalidade da solução, apresentam-se abaixo os resultados de um caso fictício de pequena dimensão.

A elevada complexidade do modelo dificulta a validação conceitual, o que reforça a necessidade de efetuar testes através de elaboração de diversos tipos de cenários, buscando analisar as respostas de acordo com as modificações postas em execução, assimilar e compreender as razões da solução apresentada. Para atingir esse objetivo, foram testados diversos cenários, dentre os quais, apresenta-se um, de escala reduzida, mas que apresenta soluções suficientes para o entendimento do problema e das potencialidades do modelo.

O modelo apresentado totaliza 2915 restrições com 1080 variáveis, sendo 882 binárias. A solução ótima foi encontrada em cerca de 64 minutos, utilizando a configuração padrão dos parâmetros de busca do CPLEX 10.0.Os navios apresentaram a programação de viagens, conforme tabela e figura abaixo. 


\begin{tabular}{|l|c|l|c|}
\hline \multicolumn{2}{|c|}{ Navio 1 } & \multicolumn{2}{c|}{ Navio 2 } \\
\hline Local & Atracação & Local & Atracação \\
\hline Plataforma 1 & N1 & Plataforma 2 & N1 \\
\hline Terminal 3 & M1 & Terminal 1 & M1 \\
\hline Plataforma 1 & N2 & Plataforma 2 & N2 \\
\hline Terminal 2 & M1 & Terminal 2 & M2 \\
\hline Plataforma 1 & N3 & Terminal 1 & M3 \\
\hline Terminal 3 & M2 & Plataforma 2 & N3 \\
\hline Terminal 1 & M2 & Terminal 2 & M3 \\
\hline Terminal 3 & M4 & Terminal 3 & M3 \\
\hline Plataforma 1 & N5 & Plataforma 1 & N4 \\
\hline Terminal 3 & M5 & Terminal 2 & M4 \\
\hline
\end{tabular}

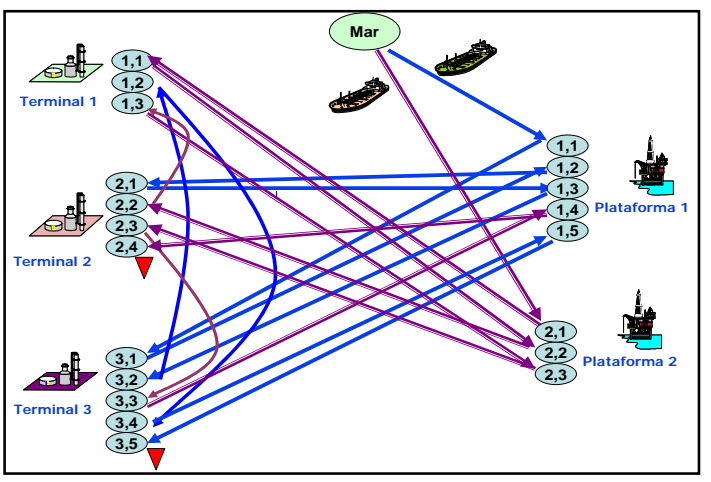

A partir da tabela e figura, observa-se que os navios iniciaram os roteiros pelas plataformas $(1,1$ e 2,1). O primeiro navio encerrou o roteiro no terminal 3, após cumprimento de dez atracações, assim como o segundo navio, que realizou o mesmo número de atracações, finalizando no terminal 2. Observase também que, em ambos roteiros, houve arcos entre os terminais. O detalhamento das operações realizadas pelo navio 1 é apresentado na Tabela 2 .

Tabela 2. Resultados do Modelo Hipotético de Otimização - Navio 1

\begin{tabular}{|c|c|c|c|c|c|c|}
\hline Navio 1 & Atracação & $\begin{array}{l}\text { Nível } \\
\text { Tanque }\end{array}$ & Volume c/d & $\begin{array}{l}\text { Carga } \\
\text { Porão }\end{array}$ & $\begin{array}{c}\text { Instante } \\
\text { Atracação }\end{array}$ & $\begin{array}{l}\text { Limite } \\
\text { Superior }\end{array}$ \\
\hline Local & & $\left(\times 10^{3} \mathrm{~m}^{3}\right)$ & $\left(\times 10^{3} \mathrm{~m}^{3}\right)$ & $\left(\times 10^{3} \mathrm{~m}^{3}\right)$ & (dia) & (dia) \\
\hline Plataforma 1 & N1 & 52 & 11 & 31 & 3,5 & 7,5 \\
\hline Terminal 3 & M1 & 9,4 & 28 & 3 & 5,3 & 7,5 \\
\hline Plataforma 1 & N2 & 52 & 10 & 13 & 9 & 13 \\
\hline Terminal 2 & M1 & 5 & 13 & 0 & 12,5 & 12,5 \\
\hline Plataforma 1 & N3 & 52,6 & 40 & 40 & 14,3 & 18 \\
\hline Terminal 3 & M2 & 7,4 & 20 & 20 & 20,3 & 21,5 \\
\hline Terminal 1 & M2 & 5 & 10 & 10 & 22,5 & 22,5 \\
\hline Terminal 3 & M4 & 5 & 10 & 0 & 36,5 & 36,5 \\
\hline Plataforma 1 & N5 & 52 & 10 & 10 & 39 & 43 \\
\hline Terminal 3 & M5 & 6,6 & 10 & 0 & 40,7 & 41,5 \\
\hline
\end{tabular}

A Tabela 2 mostra as características das atracações realizadas pelo navio 1 . As duas primeiras colunas apresentam o local e a seqüência de atracação. Na terceira coluna, são apresentados os valores dos níveis do tanque no momento da atracação; na quarta coluna, o volume carregado ou descarregado pelo navio e, na coluna seguinte, o volume de carga restante no porão do navio, no final do atendimento. A sexta coluna indica o instante em que ocorreu a atracação e última coluna indica os instantes dos limites superiores de cada atracação.

Esta tabela já indica algumas conclusões importantes do cenário avaliado. Observa-se que, na coluna referente ao volume de carga, que, por cinco vezes, foi alocado o mínimo volume atribuído (lote mínimo) e em apenas uma viagem, a capacidade total do navio fora aproveitada. Observa-se também que os níveis dos tanques nas plataformas mantiveram-se elevados e em contrapartida, os níveis dos tanques dos terminais mantiveram-se baixos, muitas vezes próximos ao limite inferior. Em grande parte do itinerário, o porão do navio esteve ocioso e os instantes de atracação ocorreram muito antes dos limites superiores, conseqüência do carregamento mínimo estabelecido. A tabela 3 mostra as características das atracações realizadas pelo navio 3. 
Tabela 3. Resultados do Modelo Hipotético de Otimização - Navio 2

\begin{tabular}{|c|c|c|c|c|c|c|}
\hline Navio 2 & Atracação & $\begin{array}{c}\text { Nível } \\
\text { Tanque }\end{array}$ & Volume c/d & $\begin{array}{l}\text { Carga } \\
\text { Porão }\end{array}$ & $\begin{array}{c}\text { Instante } \\
\text { Atracação }\end{array}$ & $\begin{array}{c}\text { Limite } \\
\text { Superior }\end{array}$ \\
\hline Local & & $\left(\times 10^{3} \mathrm{~m}^{3}\right)$ & $\left(\times 10^{3} \mathrm{~m}^{3}\right)$ & $\left(\times 10^{3} \mathrm{~m}^{3}\right)$ & (dia) & (dia) \\
\hline Plataforma 2 & N1 & 55 & 10 & 30 & 12,5 & 15 \\
\hline Terminal 1 & M1 & 12,2 & 10 & 20 & 13,9 & 17,5 \\
\hline Plataforma 2 & $\mathrm{~N} 2$ & 52 & 20 & 40 & 16 & 20 \\
\hline Terminal 2 & M2 & 5 & 27,5 & 12,5 & 19 & 19 \\
\hline Terminal 1 & M3 & 13 & 10 & 2,5 & 23,5 & 27,5 \\
\hline Plataforma 2 & N3 & 52 & 17,5 & 20 & 26 & 30 \\
\hline Terminal 2 & M3 & 13 & 10 & 10 & 28,75 & 32,75 \\
\hline Terminal 3 & M3 & 5 & 10 & 0 & 31,5 & 31,5 \\
\hline Plataforma 1 & $\mathrm{~N} 4$ & 54,9 & 10 & 10 & 35,45 & 38 \\
\hline Terminal 2 & M4 & 5 & 10 & 0 & 37,75 & 37,75 \\
\hline
\end{tabular}

A programação cumprida pelo navio 2 obedece às restrições do modelo em conjunto com o navio 1 e, de modo semelhante, o comportamento é similar, tendo sido verificadas também viagens ociosas. Dessa forma, os resultados apresentados permitem concluir que a configuração do cenário apresenta deficiências na alocação das cargas e nas viagens e um baixo aproveitamento dos recursos disponíveis.

As Tabelas 2 e 3 apresentaram os resultados em função das atracações realizadas pelos navios. Com relação aos comportamentos dos níveis dos tanques das plataformas e terminais, é preciso considerar as condições iniciais e os instantes de atracação, independentemente do navio, associados aos volumes de carga/descarga, as taxas de produção, o bombeamento e o transbordo. Os resultados são apresentados abaixo.

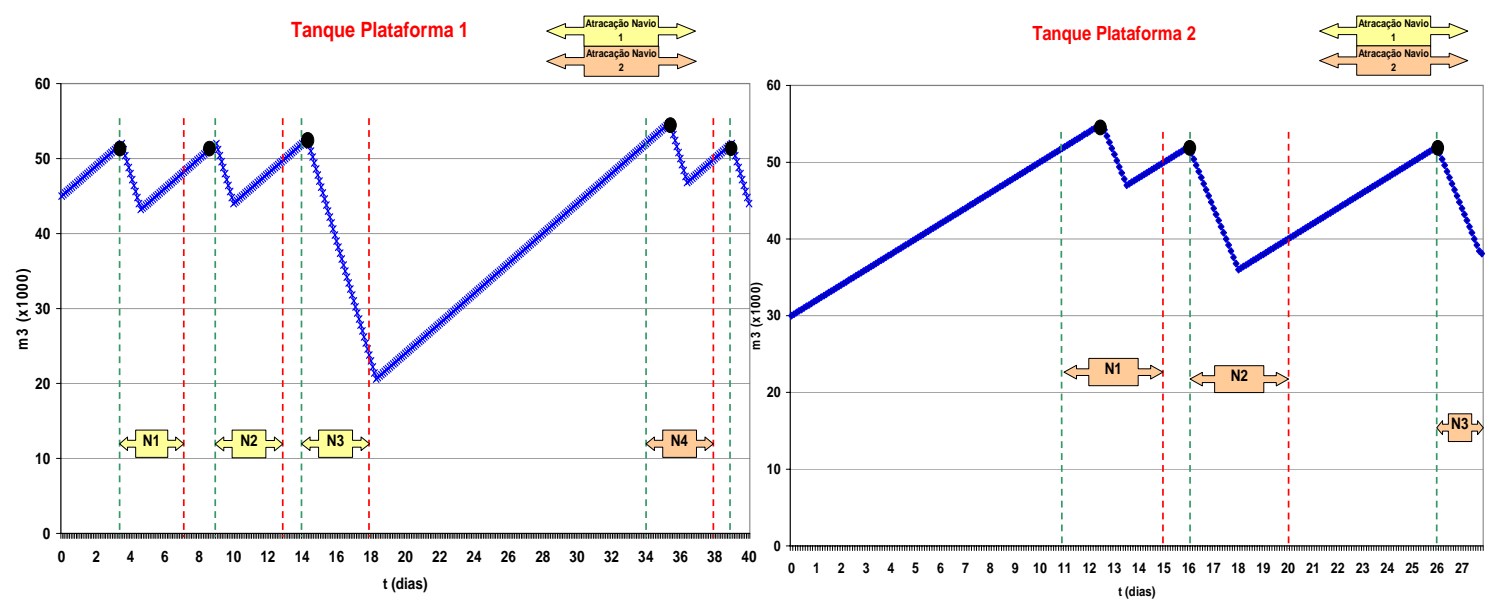

Figura 3. Tanques das Plataformas

A Figura 3 apresenta os comportamentos dos níveis de tancagens nas plataformas. Os resultados refletem fielmente as condições requeridas para controle dos níveis. A plataforma produz ou extrai um volume de petróleo segundo uma taxa constante, o que estabelece a janela de tempo para alívio ou atendimento por navio necessário para obedecer ao limite superior. No caso da plataforma 1, observa-se que o estoque inicial era de $45.000 \mathrm{~m}^{3}$ e a primeira janela de tempo foi estabelecida em [3, 7] dias. Ou seja, a primeira atracação deve ocorrer entre os instantes referentes aos dias 3 e 7 . De fato, ocorreu no dia 3 , quando a curva passa a ser descendente. O final da atracação ocorre no dia 5, quando a curva retoma o comportamento crescente, ou de produção.

Após a determinação do volume de alívio, a nova janela de tempo é recalculada para a atracação seguinte, o que ocorre novamente no limite inferior (dia 9). A terceira atracação nesta plataforma ocorre no instante do dia 14 e o volume de carga aliviado é o suficiente para postergar significativamente a data da próxima atracação, que ocorreu somente no dia 35, cujos limites foram de [34, 38]. 

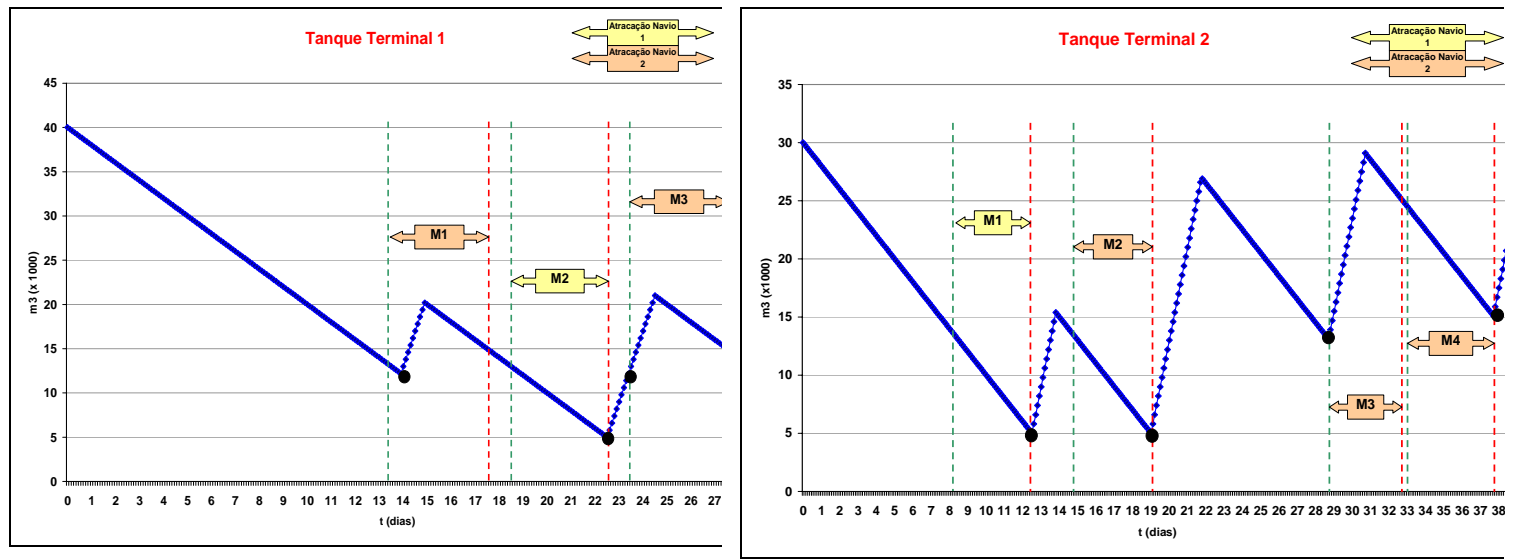

Figura 4. Tanques dos Terminais

As figuras acima ilustram os comportamentos dos níveis dos tanques nos terminais. Naturalmente, o comportamento é inverso ao observado nas plataformas, em que a partir da condição inicial, a curva é descendente, pois está associada à taxa de bombeamento ou consumo do petróleo. As atracações são definidas pelas janelas de tempo, calculadas de acordo com o tempo necessário para atendimento do limite inferior.

O conjunto de figuras permite visualização das janelas de tempo, que são dinâmicas e recalculadas de acordo com os volumes carregados e descarregados, sempre buscando obedecer às restrições de limites superiores dos tanques.

\section{CONCLUSÕES}

As oportunidades de melhorias podem ser identificadas a partir da execução de um planejamento integrado e da gestão da cadeia de suprimentos do petróleo de tal forma a buscar o emprego eficiente e racional dos recursos envolvidos.

A pesquisa mostrou que um sistema complexo desta natureza requer um tratamento sistêmico, através dos estudos de cada subsistema de forma individual e posterior integração dos mesmos a fim de quantificar e analisar a interação existente em toda a cadeia de suprimentos.

Nesse sentido, o presente trabalho apresenta uma contribuição para um enfoque sistêmico e amplo, considerando os elos de produção, armazenagem, transporte, atendimento dos navios e bombeamento do petróleo, de forma integrada. O estudo da cadeia de suprimentos do petróleo mostrou-se bastante amplo e complexo no sentido de que o enfoque sistêmico que se deseja obter a partir de uma abordagem global e concisa requer esforços ilimitados na busca de resultados eficazes e tangíveis no processo de planejamento e gestão.

O modelo de simulação apresentou os possíveis impactos que podem ser causados em um determinado elo da cadeia, a partir de perturbações no sistema originados em elos adjacentes ou distantes a este. Isso comprova a importância de se tomar a amplitude ou a abrangência da fronteira do sistema a ser estudado adequadamente.

Um enfoque sistêmico necessita principalmente da avaliação e do enquadramento do problema nos níveis hierárquicos de decisão. No processo de modelagem, a tarefa de agregação/desagregação dos eventos e dos dados associados deve ser cautelosamente ponderada e ajustada de acordo com o que se deseja obter como resposta.

Em termos de contribuições em âmbito acadêmico, destaca-se o êxito obtido na modelagem sistêmica a partir de duas técnicas de modelagem: simulação e otimização. A simulação considera e modela uma elevada quantidade de eventos, tendo sido explorada a principal vantagem da técnica: a modelagem de eventos estocásticos. As variações nos tempos associados, as condições aleatórias, os sorteios de probabilidades nas decisões de produção do petróleo, o bombeamento e a manutenção da frota de navios são alguns exemplos modelados.

Referentemente à otimização, a modelagem para obtenção da programação de navios sujeitos a condições restritivas de viagem e dos estoques nas duas pontas, a modelagem de uma demanda variável e as janelas de tempos dinâmicas são características ímpares. 
Em suma, os objetivos propostos foram atingidos com êxito, trazendo uma valiosa contribuição tanto para o meio acadêmico quanto para o setor de petróleo, que, a cada dia, vislumbra a necessidade de uma excelência não só em termos tecnológicos como também em uma gestão eficaz no planejamento de suas operações. Para a comunidade acadêmica, um problema de programação de navios em rotas distintas envolvendo múltiplas origens e múltiplos destinos, com atendimento de janela de tempo dinâmica para manutenção de níveis satisfatórios de tancagens nas duas pontas jamais fora solucionado com êxito. Para o setor, mais especificamente para os gestores dos campos maduros (infra-estrutura existente), o estudo traz uma contribuição significativa no sentido de possibilitar uma avaliação criteriosa das estratégias empregadas e oferecer alternativas de incremento nos serviços, ou mesmo servir de embasamento teórico para ratificar o sistema de programação de suas frotas no plano tático de alocação de seus recursos.

O produto mais valioso do presente trabalho envolve uma forma de abordagem que possibilita não só a aplicação no segmento de cadeia de suprimentos do petróleo mas também em sistemas semelhantes em que uma elevada quantidade de processos deve ser concomitantemente avaliada.

\section{BIBLIOGRAFIA}

1. AGÊNCIA NACIONAL DE PETRÓLEO. Anuário Estatístico 2002-2006

2. AL-KHAYYAL, F.; HWANG, S., Inventory Constrained maritime routing and scheduling for multi-commodity liquid bulk, Part I: Application and model. European Journal of Operational Research. V. 176-1, p. 106-130, 2007.

3. BISWAS, S..; NARAHARI, Y., Object oriented modeling and decision support for supply chains. European Journal of Operation Research v.153, p.704-726, 2004.

4. BOYKIN, R.F.; LEVARY, R.R., An interative decision support system for analyzing ship voyage alternatives. Interfaces. v.15, p.81-84, 1985.

5. BRAYSY, O; GENDREAU, M., Vehicle Routing Problem with Time Windows, Part I: Route Construction and local search algorithms. Transportation Science, v.39, No.1, p.104-118. 2005.

6. BROWN, G.G.; GRAVES, G.W.; RONEN, D., Scheduling ocean transportation of crude oil. Management Science. v.33, p. 335-346, 1987.

7. .CHRISTIANSEN, M; FAGERHOLT, K. Robust ship scheduling with multiple time windows. Naval Research Logistics, v.49(6), p. 611-625, 2002.

8. CHRISTIANSEN, M; FAGERHOLT, K. ; RONEN, D. Ship routing and scheduling: status and perspectives. Transportation Science, v.38.1, p. 1-18, 2004.

9. EICHMANN, D.A., Creating a High-Performance Downstream Petroleum Supply Chain. Achieving Supply Chain Excellence through Technology. p.229-232, 2000.

10. FAGERHOLT, K., Evaluating the trade-off between the level of customer service and transportation costs in a ship scheduling problem. Maritime Policy Management. v.27, n.2, p.145-153, 2000.

11. FAGERHOLT, K.; CHRISTIANSEN, M. A Combined ship scheduling and allocation problem. Journal of Operational Research, v.51(7), p. 834-842, 2000

12. FISHER, M.L.; ROSENWEIN, M.B., An Interactive Optimization System for Bulk-Cargo Ship Scheduling. Naval Research Logistics, v.36, p.27-42, 1989.

13. FROHLICH, M. T.; WESTBROOK, R., Arcs of integration: an international study of supply chain strategies. Journal of Operations Management, p.185-200, 2001.

14. FU, M.C.; GLOVER, F.W. Simulation Optimization: A review, new developments and applications. Proceedings of 2005 Winter Simulation Conference, p.83-95, 2005.

15. IAKOVOU, E. T., An interative multiobjective model for the strategic maritime transportation of petroleum products: risk analysis and routing. Safety Science. V.39, p. 19-29, 2001.

16. KOENIGSBERG E.; MEYERS, D.A., An interacting cyclic queue model of fleet operations. The Logistic and Transportation Review. v.16, p.59-71, 1980.

17. LANE, D.E.; HEAVER, E.D.; UVENO, D., Planning and Scheduling for efficiency in liner shipping. Maritime Policy Management. v.14, p.109-125, 1987.

18. PAPADAKIS, N.A.; PERAKIS,A.N., A Nonlinear Approach to the Multiorigin, Multidestination Fleet Deployment Problem. Naval Research Logistics. v.36, p.515-528, 1989.

19. PEGDEN, C. D.et. al. Introduction to Simulation Using SIMAN. McGraw-Hill, New York, 1995.

20. PERAKIS, A.N.; PAPADAKIS, N.A., Minimal time vessel routing in a time-dependent environment. Transportation Science v.23, p.266-276, 1989.

21. PERAKIS, A.N.; JARAMILLO, D.I., Fleet deployment optimization for liner shipping Part.1 Background, problem formulation and solution approaches. Maritime Policy Management v.18,n.3, p.183-200, 1991. 
22. PERSSON, J.A., GOETHE-LUNDGREN, M., Shipment Planning at oil refineries using column generation and valid inequalities. European journal of operational research. vol. 163, no3, p. 631652, 2005.

23. PETROBRAS. Plano Estratégico 2003-2007, Rio de Janeiro, 23p, 2003.

24. PIDD, M. Computer modeling for discrete event simulation. Chichester, John Wiley \& Sons, 1989.

25. RONEN, D., Short-term scheduling of vessels for ship bulk or semi-bulk commodities originating in a single area. Operations Research 34, p.164-173, 1986.

26. ROSS, A. D., Performance-based strategic resource allocation in supply networks. International Journal of Production Economics, 63, p. 255-266, 2000.

27. SHAPIRO, JEREMY F., Modeling the Supply Chain, Thompson Learning, CA, 2001

28. SHERALI, H. D.; AL-YAKOOB, S. M.; ASAN, M. M., Fleet management models and algorithms for an oil-tanker routing and scheduling problem. IIE Transactions. v.31, p.395-406, 1999.

29. SMITH, M., Improving Supply Chain Performance. Ascet, 2003

30. VIS, I. F. A. et. al., Minimum vehicle fleet size under time-window constraints at a container terminal. Transportation Science. v.39, No.2, p.249-260, 2003.

Trabalho desenvolvido com o apoio da Agência Nacional do Petróleo -ANP e da Financiadora de Estudos e Projetos - FINEP, através do Programa de Recursos Humanos da ANP para o Setor Petróleo e Gás Natural - PRH-ANP/MME/MCT. 